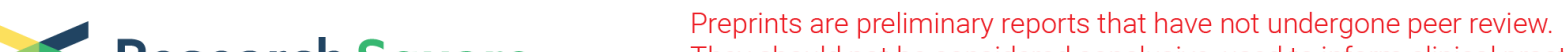

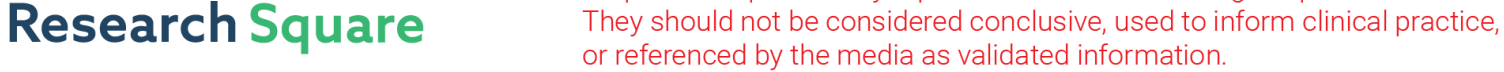 \\ elF6 Promotes the Malignant Progression of Human Hepatocellular Carcinoma via the mTOR Signaling Pathway
}

\section{Liping Sun}

Department of Pathology, School of Basic Medical Sciences, Southern Medical University

\section{Shuguang Liu}

Department of Pathology, The Eighth Affiliated Hospital, Sun Yat-sen University

\section{Xiaopai Wang}

Department of pathology, Guangzhou First People's Hospital, School of Medicine, South China University of Technology

\section{Xuefeng Zheng}

Department of Anatomy, Neuroscience Laboratory for Cognitive and Developmental Disorders, Medical College of Jinan University

\section{Ya Chen}

Department of Pathology, School of Basic Medical Sciences, Southern Medical University

Hong Shen ( $\nabla$ shenhongpathology@163.com )

Department of Pathology, School of Basic Medical Sciences, Southern Medical University; Department of Pathology, Nanfang Hospital, Southern Medical University https://orcid.org/0000-0001-5345-4709

\section{Research}

Keywords: elF6, mTOR, Hepatocellular carcinoma, Cell proliferation, Prognosis

Posted Date: September 23rd, 2020

DOI: https://doi.org/10.21203/rs.3.rs-78737/v1

License: (c) (i) This work is licensed under a Creative Commons Attribution 4.0 International License. Read Full License

Version of Record: A version of this preprint was published at Journal of Translational Medicine on May 20th, 2021. See the published version at https://doi.org/10.1186/s12967-021-02877-4. 


\section{Abstract \\ Background}

Eukaryotic translation initiation factor 6 (elF6) has a crucial function in the maturation of 60S ribosomal subunits, and it controls the initiation of protein translation. Although emerging studies indicate that elF6 is aberrantly expressed in various types of cancers, the functions and underlying molecular mechanisms of elF6 in the pathological progression of hepatocellular carcinoma (HCC) remain unclear. This study aimed to evaluate the potential diagnostic and prognostic value of elF6 in patients with HCC.

\section{Methods}

HCC samples enrolled from The Cancer Genome Atlas (TCGA), Gene Expression Omnibus (GEO) and our cohort were used to explore the role and mechanism of elF6 in HCC. The diagnostic power of elF6 was verified by receiver operating characteristic curve (ROC) analysis and its prognostic value was assessed by Kaplan-Meier analysis, and then related biological functions of elF6 were determined in vitro and in vivo cancer models. In addition, potential molecular mechanism of elF6 in HCC was unveiled by the gene set enrichment analysis and western blot assay.

\section{Results}

We demonstrated that elF6 expression was markedly increased in HCC, and elevated elF6 expression correlated with pathological progression of HCC. Besides, elF6 served as not only a new diagnostic biomarker but also an independent risk factor for OS in HCC patients. Functional studies indicated that the deletion of elF6 displayed tumor-suppressor activity in HCC cells. Furthermore, we found that elF6 could activate the mTOR-related signaling pathway and regulate the expression level of its target genes, such as CCND1, CDK4, CDK6, MYC, CASP3 and CTNNBL1, and these activities promoted proliferation and invasion of HCC cells.

\section{Conclusions}

The findings of this study provided a novel basis for understanding the potential role of elF6 in promoting tumor growth and invasion, and exploited a promising strategy for improving diagnosis and prognosis of HCC.

\section{Background}

Hepatocellular carcinoma (HCC) accounts for $80-90 \%$ of liver cancer cases and ranks as the third leading cause of cancer-related deaths worldwide [1]. Pathologically, HCC frequently derived from mature hepatocytes and is a highly heterogeneous malignancy; there are major risk factors associated with HCC, 
including HBV and HCV infection, alcohol abuse, and fatty liver disease [2]. Although its survival rate has reduced to less than $20 \%$, which is primarily attributed to enormous progress in early diagnosis, systemic immunotherapy and surgical technics, the mortality rate of HCC remains almost equal to the incidence rate, which indicates a lack of effective early diagnosis and treatment [3]. Consequently, elucidating the potential molecular pathogenesis involved in $\mathrm{HCC}$ is pivotal for improving therapeutic effectiveness and prognosis.

In recent decades, as scientists have been concerned with the origin and etiology of tumor cells to discover an effective means of prevention and treatment from the pathogenesis of tumors, dysregulation of protein translation and cancer-related pathways have been confirmed to be involved in development and progression of tumor and could affect the survival of patients diagnosed with cancer [4, 5]. All the time, eukaryotic translation initiation factors (elFs) are be considered as rate-limiting step for protein translation initiation and their disorders in the expression and location are interpreted as a cause of cancer progression and malignant biological behavior of cycling cells [6, 7]. In recent years, emerging evidence has shown that elFs play a vital role in tumor pathology. For example, when disordered or overexpressed, elF4E can trigger neoplastic transformation and result in tumorigenesis via regulating the conventional translation rate of specific proteins, and patients with elF4E-high expression tend to have a relatively dismal prognosis $[8,9]$. In contrast, obvious deletion of elF1 is revealed in pancreatic cancer samples compared with non-neoplastic pancreatic tissue [10]. From this perspective, interpreting the function of elFs in protein synthesis can be conducive to discovering the molecular mechanisms involved in cancer progression.

Eukaryotic translation initiation factor 6 (elF6), a conserved $27 \mathrm{kDa}$ protein present in eukaryotes, was discovered in mammals more than 30 years ago and considered as one of the elFs recently shown to play a role in the control of protein synthesis [11]. The majority of elF6 is present in the cytoplasm of eukaryotic cells, with a smaller but indispensable fraction ( 30\%) located in the nucleus [12-14]. On the one hand elF6 functions as an anti-association factor and prevents the assembly of the 60S and 40S ribosomal subunits in the cytoplasm $[12,15]$, but on the other hand elF6 is a component of the preribosomal particles and plays an important role in 60 S ribosome biogenesis in the nucleolus $[13,16]$. Thus, subcellular localization could be crucial for the functional regulation of elF6. Recently, emerging studies have also reported that elF6 is an important factor in carcinogenesis and tumor progression [17, 18]. Indeed, a study has emphasized that the total depletion of elF6 could delay tumorigenesis and reduced tumor growth without negative side effects on normal growth in mice, which suggested that elF6 might be an impactful therapeutic target for cancer treatment [14]. Furthermore, increasing studies confirm dysregulation of elF6 has been shown in various cancer entities, such as colorectal carcinoma (CRC) [19], malignant pleural mesothelioma (MPM) [20], ovarian adenocarcinoma (OV) [21], breast cancer (MBC) [22] and non-small cell lung cancer (NSCLC) [23]. Mechanistic studies have revealed that phosphorylation may regulate elF6 activity, and three critical phosphorylation sites have been verified. Nucleus elF6 is phosphorylated at Ser-175 and Ser-174 in vitro by the nuclear isoforms of casein kinase 1 (CK1), thus advancing the formation of pre-60S ribosomes in the cytoplasm [13]. In addition to the above two sites, the RACK1PKC 3 II complex also phosphorylates cytoplasmic elF6 at position Ser-235, which 
facilitates protein translation and carcinogenesis [12]. The upstream regulatory mechanism of elF6 has established that the transcription factor complex GA-binding protein (GABP)-binding sites are included in the elF6 promoter region, thereby regulating elF6 expression [24]. Furthermore, the Notch-1/RBP-JK signaling pathway stimulates elF6 promoter activity, enhancing the expression of elF6 and the invasiveness of ovarian cancer cells [25]. Regarding the for downstream regulation of elF6, existing studies have demonstrated that elF6 could indirectly regulate Wnt/ $\beta$-catenin signaling in CRC cells and affect CDC42 signaling in ovarian cancer cells, which promotes migration and invasion [26, 27]. Recent studies also showed that eIF6 could regulate CASP3-related apoptosis signaling in NSCLC and activate multiple AKT-related cancer signaling pathways in CRC $[23,28]$. The above evidence suggests that elF6 might be a potential tumor enhancing factor. However, its definite biological functions and regulatory mechanisms in human carcinoma including HCC remain elusive.

In the present study, we aimed to analyze the potential role and mechanism of elF6 in the tumorigenesis and progression of HCC. First, we determined that elF6 was significantly overexpressed in HCC tissues compared with normal tissues by TCGA and GEO databases, which was subsequently verified by IHC and western blot. Based on the analysis of clinicopathological parameters, we also found that high levels of elF6 had a positive correlation with tumor progression, and elF6 may serve as a potential diagnostic and prognostic biomarker for HCC patients. In addition, functional studies indicated that elF6 was a potential driver of tumor biological processes in vitro and in vivo cancer models. Moreover, through signal pathway enrichment analysis and verification based on western blot assay, we confirmed that elF6 could activate mTOR-related cancer signaling pathways and thereby regulate downstream genes, such as MYC, CDK4, CDK6, CCND1, CASP3 and CTNNBL1, to affect cell proliferation, the cell cycle, apoptosis and invasion in HCC. Our studies elucidated the crucial role of elF6 in the progression of HCC and provided a potentially valuable biomarker for the diagnosis and prognosis of this cancer.

\section{Methods}

\section{Data mining and bioinformatics analysis}

The gene expression data for hepatocellular cancer $(n=374)$ and adjacent normal tissues $(n=50)$ were downloaded from The Cancer Genome Atlas (TCGA) database (https://www.cancer.gov/tcga). Meanwhile, four elF6 expression profiles (GSE64041, GSE57957, GSE45436 and GSE14520) were obtained from the Gene Expression Omnibus (GEO) database (http://www.ncbi.nlm.nih.gov/geo). All bioinformatics data were analyzed using $\mathrm{R}$ software, and fold change $\geq 2$ and $p$-values $\leq 0.05$ were regarded as statistically significant. The sets of genes which encode proteins interacting with elF6 were downloaded from UniHI websites (http://www.unihi.org) and then entered into online Metascape (http://www.metascape.org) to perform the pathway enrichment analysis. The data for genes associated with biological function of elF6 in HCC were downloaded from the R2: Genomics Analysis and Visualization Platform (https://hgserver2.amc.nl/cgi-bin/r2/main.cgi) to analyze the linear correlation of elF6 with these genes. The Kaplan-Meier Plotter website (http://kmplot.com/analysis/) was used to analyze overall survival (OS) in patients with HCC. The picture and log rank $p$-values are obtained online. 


\section{Clinical specimens}

The clinical specimens, including formalin-fixed paraffin-embedded human HCC specimens $(n=68)$ and fresh surgically removed HCC tissues $(n=6)$, were collected from Affiliated Nanfang Hospital of Southern Medical University (Guangzhou, China) between 2018 and 2020. All tissues were diagnosed as HCC by clinical pathological analysis. Detailed clinical data and information of the specimens were supplied in Supplementary Table S1. The study was conducted with written informed consent of all patients and the approval of the Southern Medical University Ethics Committee (Guangzhou, China).

\section{Cell culture}

Human HCC cell lines, SMMC7721, Huh7, HepG2, BEL-7404, BEL-7402, 97H, BEL-7405, HB611 and human normal liver cells (LO2), were obtained from the Culture Collection of the Chinese Academy of Science (Shanghai, China) in 2019. Human HCC cell lines were maintained in RPMI 1640 media (Gibco, USA) containing 10\% fetal bovine serum (FBS) (Gibco, USA). LO2 cells were cultured in DMEM (Gibco, USA) supplemented with $10 \% \mathrm{FBS}$. All cells were incubated in a $37^{\circ} \mathrm{C}$ thermostatic incubator with $5 \% \mathrm{CO}_{2}$ (Thermo, USA).

\section{Western blotting}

Total proteins were extracted from tissues or cells using RIPA buffer (KeyGEN, China) containing a protease inhibitor (KeyGEN, China) cocktail. The protein concentration was determined using a BCA Protein Assay kit (KeyGEN, China). Proteins were separated by 10-12\% SDS-PAGE and transferred onto polyvinylidene difluoride (PVDF) membranes (Millipore, USA). PVDF membranes were blocked with $5 \%$ nonfat milk in 1\% Tween-PBS (TBST) for $2 \mathrm{~h}$ at room temperature and then incubated with the specific primary antibodies (Table 1) overnight at $4^{\circ} \mathrm{C}$. After washing three times for 10 min each in TBST, membranes were incubated with their respective second antibodies (Table 1) for $1 \mathrm{~h}$ at room temperature. Blots were probed using the Pierce ECL Western Blotting Substrate (KeyGEN, China) and chemiluminescence imaging system (Tanon, China). The grey values of the protein bands were quantified by ImageJ software and $\beta$-actin was used as the internal control.

\section{Immunohistochemistry (IHC) staining}

The immunohistochemistry $(\mathrm{IHC})$ staining procedure was based on previous methods mentioned in the literature [29]. Antibodies specific to elF6 and Ki67 (Table 1) were applied according to the manufacturer's protocol. IHC score (H-score) was used to quantify the expression of elF6 based on the literature [23].

\section{Lentiviral vector transduction}

Lentiviral vectors repressing elF6 were constructed by GenePharma Company (Suzhou, China) and were used to infect HCC cells to establish stable cell lines that repressed elF6. Cells $\left(1 \times 10^{6} /\right.$ well) were seeded into six-well plates and transfected with lentiviral after the confluence of cells reached $60 \%$. Then, transfected cells was selected by RPMl 1640 media containing $4 \mu \mathrm{g} / \mathrm{mL}$ puromycin for $72 \mathrm{~h}$ and 
maintained with $1 \mu \mathrm{g} / \mathrm{mL}$ puromycin. Transduction efficiency was identified for subsequent experiments by western blotting.

\section{Cell proliferation assay and colony formation assay}

Cell proliferation was measured using a Cell Counting Kit-8 (CCK-8) (Dojindo, Japan). Control and transfected $\mathrm{HCC}$ cells at equal densities (1000 cells/well) were seeded into 96 -well plates and cultured at $37^{\circ} \mathrm{C}$ with $5 \% \mathrm{CO}_{2}$. Then, $10 \mu \mathrm{l} \mathrm{CCK-8} \mathrm{reagent} \mathrm{was} \mathrm{added} \mathrm{to} \mathrm{each} \mathrm{well} \mathrm{at} 0,1,2,3,4$ and 5 days after plating. The plate was incubated for an additional $2 \mathrm{~h}$ at $37^{\circ} \mathrm{C}$ and the optical density (OD) was measured at $450 \mathrm{~nm}$ using automatic enzyme labeling (Molecular Devices, Sunnyvale, CA). Each sample was independently repeated 3 times in triplicate. The colony formation assay was performed as previously described in the literature [30].

\section{Cell cycle and apoptosis analysis}

HCC cells transfected with lentiviral repressing elF6 or the control group were plated into 6-well plates. After the confluence of cells reached $70-80 \%$, the cells were digested with EDTA-free trypsin and collected in binding buffer. Cell cycle and apoptosis assays were performed with the Cell Cycle Detection Kit (KeyGEN, China) and Annexin V-APC/7-AAD Apoptosis Detection Kit (KeyGEN, China) according to the manufacturer's instruction, respectively. The flow cytometry result was assessed using a BD FACSCanto II flow cytometer (BD Biosciences) with ModFit LT software (Verity Software House, Topsham, ME). Each assay was repeated three times.

\section{Cell transwell Matrigel invasion assays}

A transwell-Matrigel assay was used to verify cell invasion ability. The special chambers with an 8- $\mu \mathrm{m}$ pore size (Corning, USA) were plated into 24-well plates and coated with $50 \mu \mathrm{L}$ of Matrigel (dilutions 1:5 in RPMI 1640 media; BD, USA) for $4 \mathrm{~h}$. Treated cells $\left(1 \times 10^{5} /\right.$ well) suspended in $200 \mu \mathrm{L}$ serum-free medium were added to the upper chamber, and $600 \mu \mathrm{L} 1640$ medium supplemented with $15 \%$ FBS was added to the lower chambers. After culturing in a $37^{\circ} \mathrm{C}$ thermostatic incubator for $24 \mathrm{~h}$, the cells that invaded into the underside of the transwell chambers were fixed with $4 \%$ paraformaldehyde for $30 \mathrm{~min}$ and stained with $0.1 \%$ crystal violet for $20 \mathrm{~min}$ at room temperature. The number of invasive cells was counted in 5 visual fields under a microscope (Olympus, Japan).

\section{Subcutaneous xenograft experiment}

Female 4- to 5-week-old BALB/c-nu (nude) mice were purchased from the Animal Center of Guangdong Province (Guangzhou, China) and were maintained in the SPF Animal Laboratory. BEL-7404 cells $\left(1 \times 10^{7}\right.$ in $100 \mu \mathrm{L}$ PBS per mouse) stably transfected with elF6 silenced lentiviruses (ShelF6) or control lentiviruses (ShNC) were injected into the subcutaneous tissues of nude mice ( $\mathrm{n}=6$ per group). The tumor size was measured using Vernier calipers, and the tumor volume was calculated by the formula $(V=1 / 2 \times$ length $\times$ width $\times$ height) [31]. After four weeks, nude mice were sacrificed by anesthesia, and tumors 
were perfectly excised and then weighed and fixed with $10 \%$ neutral-buffered formalin overnight. The 4$\mu \mathrm{m}$ sections prepared were stained with hematoxylin-eosin (HE) and IHC staining using anti-Ki67 according to standard protocols. All animal experiments were performed in compliance with protocols approved by the Animal Care and Use Committee of Southern Medical University.

\section{Statistical analysis}

All statistical analyses were evaluated using SPSS 22.0 software. Quantitative data from three independent experiments are indicated as the means \pm standard (means $\pm S D$ ). One-way ANOVA or twotailed Student's t-test were conducted for the comparisons among groups. Chi-square $\left(\chi^{2}\right)$ tests were used to analyze relationships between elF6 expression and clinicopathologic characteristics. The Kaplan-Meier method was performed for survival analysis. Spearman's correlation coefficient was used to examine the linear relationship between elF6 and target genes in HCC tissues. $p<0.05$ was regarded as statistically significant.

\section{Results}

elF6 is overexpressed in HCC clinical samples and cell lines

We analyzed a total of 424 elF6 expression profiles from the TCGA liver carcinoma dataset, including 50 normal tissues and 374 tumor tissues. The results showed that elF6 expression was higher in HCC tissue than in normal liver tissue ( $p$ <0.001) (Fig. 1a). Furthermore, the expression of elF6 was also significantly elevated in HCC tissues compared with normal liver tissues by the GEO dataset, including GSE64041, GSE14520, GSE57957, and GSE45436 (all $p<0.001$ ) (Fig. 1b-e).

To further validate the above bioinformatics findings, we evaluated the expression levels of elF6 in 6 paired fresh HCC tissues and their adjacent normal liver tissues by western blot. As shown in Fig. 2a and $b$, elF6 levels were evidently increased in fresh HCC tissues $(p<0.05)$. Meanwhile, the relative protein level of elF6 was significantly upregulated in 7 HCC cell lines (SMMC7721, Huh7, HepG2, BEL-7404, HB611, 97H, BEL-7405) compared with that in normal liver cells (LO2) and was much higher in BEL-7404 and 97H cells $(p<0.05)$ (Fig. $2 c$ ). Furthermore, we also performed an IHC assay to verify the above results. The paraffin-embedded tissues were diagnosed as HCC based on HE staining before collection, and elF6 was mainly located in the cytoplasm, as shown by IHC staining (Fig. 2d). Moreover, statistical analysis showed that the expression of elF6 was distinctly elevated in $64.71 \%(44 / 68)$ of HCC tissues (Table 2), and its high expression was more than that of normal liver tissues $(p<0.001)$ (Fig. $2 e)$.

\section{elF6 expressionis positively correlated with tumor size, vascular invasion and poor prognosis in HCC patients}

To further investigate the role of elF6 in the development of HCC, we analyzed the relationship between the expression of elF6 and the clinical characteristics of HCC patients from IHC results. The $68 \mathrm{HCC}$ patients were divided into the elF6-high expression group $(n=44)$ and the elF6-low expression group 
$(n=24)$, and the clinical features of these patients are summarized in Table 2. The data show that the expression of elF6 was significantly correlated with tumor size $(p<0.001)$ (Fig. 2f) and vascular invasion $(p<0.001)$ (Fig. $2 g$ ). In other words, patients with large tumor diameters or vascular invasion occurrences were frequently identified with elF6 overexpression. However, elF6 overexpression had no relationship with other clinicopathological features, including gender, age, differentiation, lymphatic metastasis, distant metastasis, HBV infection, AFP level, and liver cirrhosis occurrence. Kaplan-Meier survival curves indicated that overall survival (OS) time of the elF6 high expression group was significantly shorter than that of the elF6-low expression group from the TCGA public database $(p=0.015)$ (Fig. $2 h)$. These results indicate that the expression of elF6 is correlated with tumor size, vascular invasion and poor prognosis in HCC patients.

\section{elF6 expression is a reliable clinical diagnostic biomarker for HCC}

We established ROC curves to evaluate the clinical diagnostic value of elF6 in HCC. The area under the ROC curve (AUC) from TCGA was 0.902 and indicated a high diagnostic power (Fig. 3a). Meanwhile, the AUC values from GSE64041, GSE14520, GSE57957 and GSE45436 further validated this result (Fig. 3be). The ROC curve of the elF6 protein also showed authentic diagnostic value in our IHC results (AUC=0.884) (Fig. 3f).

\section{Knockdown of elF6inhibits the malignant progression of HCC cells in vitro}

To determine the possible biological role of elF6 in HCC cells, we constructed stable elF6 knockdown BEL7404 and $97 \mathrm{H}$ cell lines. The infection efficiency was measured by western blotting $(p<0.001)$ (Fig. 4a, b). The results of CCK-8 assays revealed that the proliferation activity of elF6 knockdown cells was deeply decreased compared with that of their control cells (Fig. 4c, d). The quantitative analysis from plate colony assays suggested that the number of colonies formed by elF6 knockdown cells was markedly lower than that of the control cells $(p<0.001)$ (Fig. 4e). Furthermore, the invasive capabilities of HCC cells were assessed by Transwell assays with Matrigel. We found that elF6 knockdown dramatically decreased the number of invasive cells passing through the Matrigel to the underside of the membrane $(p<0.001)$ (Fig. 4f).

We also detected the effect of elF6 on apoptosis and the cell cycle in BEL-7404 and 97H cells by flow cytometry assay. As shown in Fig. 5a, knockdown of elF6 increased the proportion of BEL-7404 and 97H cells in G0/G1 phase, but decreased the proportion of cells in $S$ phase, which was similar to the proliferation assay results. For cell apoptosis, knockdown of elF6 induced a significant increase in the total apoptosis rate in BEL-7404 cells $(p<0.01)$ and $97 \mathrm{H}$ cells $(p<0.001)$ (Fig. 5b). Accordingly, these results showed that the increase in cell cycle G0/G1-phase arrest and apoptosis might contribute to the suppression of cell proliferation after depletion of elF6.

\section{Knockdown of elF6 arrested tumor growth in a nude subcutaneous xenograft model.}


The effect of elF6 on HCC cell growth was further confirmed in a nude mouse xenograft model. Cells treated with the elF6 knockdown (BEL-7404-shelF6) and control (BEL-7404-shNC) were injected into nude subcutaneous tissue, and the tumor size was measured every two days. BEL-7404-shelF6 cells injected into nude mice developed smaller $(p<0.05)$ and lighter tumor $(p<0.01)$ with slower growth rates compared with those in the control $(n=6)$ (Fig. 6a-c). Finally, IHC staining of Ki-67 antibody indicated that the Ki-67 index in the BEL-7404-shelF6 groups was lower than those that in the control group $(p<0.05)$ (Fig. $6 \mathrm{~d}, e)$, further confirming that elF6 knockdown inhibited HCC cell proliferation in vivo.

\section{The potential regulatory network and functional enrichment analysis of elF6 in HCC}

To further investigate the potential signaling pathways by which elF6 promoted tumor malignant progression, we examined 355 elF6-associated proteins using UniHI websites (the details given in Supplementary Table S2) and then constructed an elF6 centered network showing the top 20 proteins using GeneMANIA (Fig. 7a). Subsequently, we submitted them to the Metascape online website for pathway enrichment analysis. The results showed that the associated proteins received a high

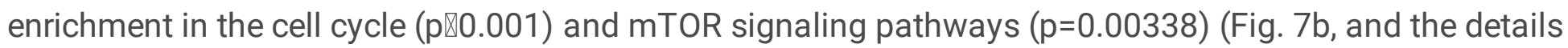
are shown in Supplementary Table S3), which are associated with the malignant proliferation of tumor cells.

\section{elF6 activated mTOR-related cancer signaling pathways in HCC progression}

To confirm above result of enrichment analysis, we examined the effect of elF6 knockdown on mTOR activity by western blotting. As shown in Fig. 8a, elF6 knockdown dramatically decreased the phosphorylated-mTOR (p-mTOR) level in HCC cell lines. At the same time, cell cycle and invasion regulators, including MYC, CCND1, CDK4, CDK6 and CTNNBL1, were downregulated after elF6 knockdown, while the apoptosis regulator cleaved-CASP3 was upregulated (Fig. 8b). The detection of a coefficient correlation between elF6 and the above related markers showed that elF6 expression was positively correlated with MYC, CCND1, CDK4, CDK6 and CTNNBL1 (Fig. 8c-g), which was consistent with the western blot results. Consequently, we concluded that elF6 activated mTOR-related multiple cancer signaling pathways to promote the malignant progression of human HCC (Fig. 8h).

\section{Discussion}

Liver cancer is one of the most common malignancies with a high mortality rate. According to the latest cancer statistics of 2020 , liver cancer is increasing by $2-3 \%$ annually with the most rapid speed during 2007 through 2016, and the 5-year relative survival rate is especially dismal [32]. Although diagnostic techniques and therapeutic methods have become more abundant for liver cancer, the improvement of its prognosis remains disappointing [33]. In recent years, exploring specific biomarkers and applying them to clinical prognosis evaluation have become one of the leading research hotspots of cancer [34].

elFs play important roles in controlling the translation of proteins regulating cell growth, apoptosis, and malignant transformation [35,36]. As a result of characteristics of active protein synthesis in tumor cells, 
elFs are considered to be dysregulated and conducive to malignant progression during carcinogenesis. Indeed, relevant evidences have demonstrated that elFs overexpression is an important part of the tumorigenesis in numerous patients. For example, elF4E overexpression is frequently found in patients with colorectal cancer (CRC) or breast cancer (BC) [37, 38]; elF5A2 overexpression is obviously associated with the advanced stage of ovarian cancer [39]; eIF3D increases cell cycle progression and motility in prostate cancer ( $\mathrm{PCa}$ ) [40]. However, the roles of elFs in the development and progression of HCC remain limited.

In recent years, the protein elF6 became included in the family of eukaryotic translation initiation factors controlling growth factor-induced tumors. It is reported that elF6, as a dual factor, not only facilitates ribosome biogenesis, but also prevents assembly of the $40 \mathrm{~S}$ and $60 \mathrm{~S}$ ribosomal subunit [12, 24]. Notably, earlier studies approved that elF6 downregulation can cause abnormal embryonic development by the G1/S block of the cell cycle in Xenopus [41], and depletion of elF6 reduced cell proliferation and viability in Saccharomyces cerevisiae [42]. Moreover, knockout of elF6 in mice avoided MYC-induced lymphomagenesis and prolonged tumor-free survival tumor growth [14]. These above studies point out the important cellular role of elF6 in cell cycle progression and tumorigenesis. Furthermore, recent studies approved that elF6 was dysregulated in various cancers, such as malignant pleural mesothelioma (MPM) [20], Gallbladder cancer (GBC) [43], ovarian serous carcinoma (OV) [21], colorectal cancer (CRC) [19] and non-small cell lung cancer (NSCLC) [23]. In CRC, OV and MPM, elF6 is overexpressed in tumor tissue compared to non-neoplastic tissue, highlighting that elF6 as a potential new biomarker had a pivotal contribution to pathologic process $[19,21,23]$. In this study, we firstly provided evidence that elF6 was overexpressed in HCC compared to non-neoplastic liver tissue, and that it might be an important clinical diagnostic biomarker for HCC patients. Our TCGA data set indicated elF6 overexpression reduced patients' overall survival in HCC, which was in accord with existing results from NSCLC and OV [21, 23], highly suggesting that it was a predictor for overall survival in HCC. Thus, examining the RNA or protein quantification of elF6 could contribute to predict the occurrence of HCC, and directly targeting elF6 by genetic interference technique might improve therapeutic efficacy.

To further confirm elF6 as a novel promising target for HCC, we performed knockdown experiments to investigate the biological function of elF6 in vivo and in vitro cancer model. After successful knockdown of elF6, the cell growth rate, tumorigenesis and invasive capability of BEL-7404 and 97H cells were significantly suppressed. This confirms previous reported studies, where elF6 knockdown in CRC cells significantly reduced proliferation and colonogenicity [19], while elF6 overexpression enhanced the migratory phenotype by augmenting CDC42 translation in ovarian cancer [26]. The occurrence of tumor is related to not only abnormal proliferation and differentiation of cells but also abnormal apoptosis. Thus, the spontaneous apoptosis of malignant tumor may involve the therapeutic effect of tumor regression [44]. In our study, we also analyzed apoptosis levels, and found that elF6 knockdown significantly increased apoptosis ratio in transfected HCC cells. According to a published data, elF6 silencing not only obviously induces CASP3-dependent apoptosis in NSCLC cells but also elevates SA- $\beta$-Gal activity and p21 levels, which is not conducive to the induction of cellular senescence pathways [45], suggesting that elF6 might have initiated cell death, but this effect are prevented because of effector CASP3 inhibition, 
thereby cells emit persistent mitogen signaling and develop into an excessive proliferating population. However, specific molecular mechanisms of elF6 in these biological processes seem to be indecisive and remain to be fully elucidated.

The current study revealed that elF6-related signaling pathways activated in HCC were enriched in ribosome biogenesis, cell cycle and mTOR-related cancer signaling pathway, which may stimulate tumor proliferation and invasion. The mTOR pathway plays a crucial role in adapting ribosome biogenesis, gene expression and protein translation to surrounding conditions of the cells [43], and the phosphorylation of mTOR signaling pathway molecules and the activation of its downstream proteins promote the proliferation, metabolism and angiogenesis in many cancers [46, 47]. Contrarily, suppression of mTOR effectively inhibits tumor growth and prolongs survival in cancers [48]. Thus, targeting mTOR can contribute to explore novel therapeutic strategies of anticancer. The elF signaling cascade is mainly regulated via the $\mathrm{PISK} / \mathrm{AKT} / \mathrm{mTOR}$ pathway due to its vital role in regulating cell growth and proliferation $[49,50]$. Moreover,it is confirmed that elF6 can positively regulate AKT-related cancer signaling and contribute to the malignant behavior of CRC [28]. Most strikingly, an immunohistochemical study in HCC indicated that elF6 could be involved in the regulation of mTOR pathway [51], but this was not verified by sufficient experimental data. We detected with western blot that phosphorylated mTOR (p-mTOR) was downregulated following attenuation of elF6 expression, confirming that elF6 positively regulated mTOR signaling. Consistent with this result, the expression level of elF6 mRNA had a positive correlation with the mRNAs involved in the arrest of the G0/G1 cell cycle, proliferation, and invasion, including MYC, CDK4, CDK6, CCND1 and CTNNBL1, while a negative correlation with the apoptotic marker cleavedCASP3, which indicated that some of the biomarkers had altered steady state mRNA levels upon elF6 overexpression, thereby resulting in upregulation of protein expression. In other words, elF6 is likely to control their expression via the translational regulation of some transcription factors. Thus, our findings indicated that elF6 promoted the malignant progression of HCC via the mTOR signaling pathway, which provided a theoretical basis for HCC treatment by targeting elF6.

Although relevant studies have confirmed that the GABP complex regulates the transcription of elF6 and that the Notch-I signaling pathway stimulates the activity of elF6 promoter in lymphoblastoid and ovarian cancer cell lines [24, 25]. However, the upstream regulatory mechanism involved in elF6 has not been investigated in our study and further study on this mechanism is required to be performed. Moreover, we should treat HCC cells or animal models with mTOR pathway inhibitors or stimulators and further detect the precise and detailed regulatory mechanisms between elF6 and mTOR-related signal molecules.

\section{Conclusion}

Our findings illustrated that elF6 overexpression was not only observed in HCC, but also correlated with malignant progression and poorer prognosis. elF6 might serve as a promising biomarker for the HCC diagnosis in immunohistochemistry and its regulation could be used in the future as a novel potential therapeutic target in HCC. 


\section{Abbreviations}

elF6: eukaryotic translation initiation factor 6; HCC:hepatocellular carcinoma; TCGA:The Cancer Genome Atlas; GEO:Gene Expression Omnibus; ROC:eceiver operating characteristic curve; CCND1:cyclin D1; CDK4:cyclin dependent kinase 4; CDK6:cyclin dependent kinase 6; MYC:MYC proto-oncogene, bHLH transcription factor; CTNNBL1:catenin beta like 1; IHC:Immunohistochemistry; FBS:Fetal bovine serum; MF:Molecular function;BP:Biological process; CC:Cellular component.

\section{Declarations}

\section{Availability of data and materials}

All data generated or analysed during this study are included in this published article.

\section{Ethics approval and consent to participate}

This study was approved by the Southern Medical University Ethics Institutional Board (Guangzhou, China). Written informed consents were obtained from all patients before operation.

\section{Consent for publication}

Informed consent was obtained from all individual participants included in this study.

\section{Competing interests}

There is no competing financial interest among authors.

\section{Funding}

This study was supported by grants from Futian District Health Public Welfare Scientific Research Project of Shenzhen (grant no. FTWS2018043, FTWS2019014 and FTWS2018047).

\section{Authors' contributions}

LPS and SGL conceived the idea of the study. LPS participated in the experimental design and drafted and revised the article. SGL collected and analyzed the data from the bioinformatics database. XPW scored and graded the immunohistochemical results. XFZ performed the statistical analysis and revised the article. YC collected tissue samples. HS supervised the study and revised the article. All authors read and approved the final article before its submission.

\section{Acknowledgments}


We are grateful for the help and support of all authors who contributed to the data analysis and statistics. The results presented in this study are in part based on database sites and software, such as TCGA database (https://www.cancer.gov/tcga) and GEO database (http://www.ncbi.nlm.nih.gov/geo).

\section{References}

1. Bray F, Ferlay J, Soerjomataram I, Siegel R L, Torre L A, Jemal A. Global cancer statistics 2018 : GLOBOCAN estimates of incidence and mortality worldwide for 36 cancers in 185 countries. CA Cancer J Clin. 2018;68(6):394-424.

2. Islami F, Goding S A, Miller K D, Siegel R L, Fedewa S A, Jacobs E J, et al. Proportion and number of cancer cases and deaths attributable to potentially modifiable risk factors in the United States. CA Cancer J Clin. 2018;68(1):31-54.

3. Allemani C, Matsuda T, Di Carlo V, Harewood R, Matz M, Niksic M, et al. Global surveillance of trends in cancer survival 2000-14 (CONCORD-3): analysis of individual records for 37513025 patients diagnosed with one of 18 cancers from 322 population-based registries in 71 countries. Lancet. 2018;391(10125):1023-1075.

4. Ramamurthy V P, Ramalingam S, Kwegyir-Afful A K, Hussain A, Njar V C. Targeting of protein translation as a new treatment paradigm for prostate cancer. Curr Opin Oncol. 2017;3:210-220.

5. Showkat M, Beigh M A, Andrabi K I. mTOR Signaling in Protein Translation Regulation: Implications in Cancer Genesis and Therapeutic Interventions. Mol Biol Int. 2014;2014:686984.

6. Graff J R, Konicek B W, Lynch R L, Dumstorf C A, Dowless M S, Mcnulty A M, et al. elF4E activation is commonly elevated in advanced human prostate cancers and significantly related to reduced patient survival. Cancer Res. 2009;69(9):3866-3873.

7. Smolle M A, Czapiewski P, Lapinska-Szumczyk S, Majewska H, Supernat A, Zaczek A, et al. The Prognostic Significance of Eukaryotic Translation Initiation Factors (elFs) in Endometrial Cancer. Int J Mol Sci. 2019;20(24):6169.

8. Bitterman P B, Polunovsky V A. elF4E-mediated translational control of cancer incidence. Biochim Biophys Acta. 2015;1849(7):774-780.

9. Niu Z, Xu P, Zhu D, Tang W, Ji M, Lin Q, et al. Integrin beta1 mediates 5-fluorouracil chemoresistance under translational control of elF4E in colorectal cancer. Int J Clin Exp Pathol. 2018;11(10):47714783.

10. Golob-Schwarzl N, Puchas P, Gogg-Kamerer M, Weichert W, Goppert B, Haybaeck J. New Pancreatic Cancer Biomarkers elF1, elF2D, elF3C and elF6 Play a Major Role in Translational Control in Ductal Adenocarcinoma. Anticancer Res. 2020;40(6):3109-3118.

11. Biffo S, Sanvito F, Costa S, Preve L, Pignatelli R, Spinardi L, et al. Isolation of a novel beta4 integrinbinding protein (p27(BBP)) highly expressed in epithelial cells. J Biol Chem. 1997;272(48):3031430321. 
12. Ceci M, Gaviraghi C, Gorrini C, Sala L A, Offenhauser N, Marchisio P C, et al. Release of elF6 (p27BBP) from the 60S subunit allows 80 S ribosome assembly. Nature. 2003;426(6966):579-584.

13. Miluzio A, Beugnet A, Volta V, Biffo S. Eukaryotic initiation factor 6 mediates a continuum between $60 S$ ribosome biogenesis and translation. EMBO Rep. 2009;10(5):459-465.

14. Miluzio A, Beugnet A, Grosso S, Brina D, Mancino M, Campaner S, et al. Impairment of cytoplasmic elF6 activity restricts lymphomagenesis and tumor progression without affecting normal growth. Cancer Cell. 2011;19(6):765-775.

15. Valenzuela D M, Chaudhuri A, Maitra U. Eukaryotic ribosomal subunit anti-association activity of calf liver is contained in a single polypeptide chain protein of $\mathrm{Mr}=25,500$ (eukaryotic initiation factor 6 ). J Biol Chem. 1982;257(13):7712-7719.

16. Sanvito F, Piatti S, Villa A, Bossi M, Lucchini G, Marchisio P C, et al. The beta4 integrin interactor $\mathrm{p} 27(\mathrm{BBP} / \mathrm{elF} 6)$ is an essential nuclear matrix protein involved in $60 \mathrm{~S}$ ribosomal subunit assembly. $\mathrm{J}$ Cell Biol. 1999;144(5):823-837.

17. Brina D, Miluzio A, Ricciardi S, Biffo S. elF6 anti-association activity is required for ribosome biogenesis, translational control and tumor progression. Biochim Biophys Acta. 2015;1849(7):830835.

18. Brina D, Grosso S, Miluzio A, Biffo S. Translational control by $80 S$ formation and 605 availability: the central role of elF6, a rate limiting factor in cell cycle progression and tumorigenesis. Cell Cycle. 2011;10(20):3441-3446.

19. Golob-Schwarzl N, Schweiger C, Koller C, Krassnig S, Gogg-Kamerer M, Gantenbein N, et al. Separation of low and high grade colon and rectum carcinoma by eukaryotic translation initiation factors 1, 5 and 6. Oncotarget. 2017;8(60):101224-101243.

20. Miluzio A, Oliveto S, Pesce E, Mutti L, Murer B, Grosso S, et al. Expression and activity of elF6 trigger malignant pleural mesothelioma growth in vivo. Oncotarget. 2015;6(35):37471-37485.

21. Flavin R J, Smyth P C, Finn S P, Laios A, O'Toole S A, Barrett C, et al. Altered elF6 and Dicer expression is associated with clinicopathological features in ovarian serous carcinoma patients. Mod Pathol. 2008;21(6):676-684.

22. Gatza M L, Silva G O, Parker J S, Fan C, Perou C M. An integrated genomics approach identifies drivers of proliferation in luminal-subtype human breast cancer. Nat Genet. 2014;46(10):1051-1059.

23. Gantenbein N, Bernhart E, Anders I, Golob-Schwarzl N, Krassnig S, Wodlej C, et al. Influence of eukaryotic translation initiation factor 6 on non-small cell lung cancer development and progression. Eur J Cancer. 2018;101:165-180.

24. Donadini A, Giacopelli F, Ravazzolo R, Gandin V, Marchisio P C, Biffo S. GABP complex regulates transcription of elF6 (p27BBP), an essential trans-acting factor in ribosome biogenesis. FEBS Lett. 2006;580(8):1983-1987.

25. Benelli D, Cialfi S, Pinzaglia M, Talora C, Londei P. The translation factor elF6 is a Notch-dependent regulator of cell migration and invasion. PLoS One. 2012;7(2):e32047. 
26. Pinzaglia M, Montaldo C, Polinari D, Simone M, La Teana A, Tripodi M, et al. EIF6 over-expression increases the motility and invasiveness of cancer cells by modulating the expression of a critical subset of membrane-bound proteins. BMC Cancer. 2015;15:131.

27. Ji Y, Shah S, Soanes K, Islam M N, Hoxter B, Biffo S, et al. Eukaryotic initiation factor 6 selectively regulates Wnt signaling and beta-catenin protein synthesis. Oncogene. 2008;27(6):755-762.

28. Lin J, Yu X, Xie L, Wang P, Li T, Xiao Y, et al. elF6 Promotes Colorectal Cancer Proliferation and Invasion by Regulating AKT-Related Signaling Pathways. J Biomed Nanotechnol. 2019;15(7):15561567.

29. Xiang J, Fang L, Luo Y, Yang Z, Liao Y, Cui J, et al. Levels of human replication factor C4, a clamp loader, correlate with tumor progression and predict the prognosis for colorectal cancer. J Transl Med. 2014;12:320.

30. Li J, Xia R, Liu T, Cai X, Geng G. LncRNA-ATB Promotes Lung Squamous Carcinoma Cell Proliferation, Migration, and Invasion by Targeting microRNA-590-5p/NF90 Axis. DNA Cell Biol. 2020;39(3):459473.

31. Lin C, Zhang J, Lu Y, Li X, Zhang W, Zhang W, et al. NIT1 suppresses tumour proliferation by activating the TGFbeta1-Smad2/3 signalling pathway in colorectal cancer. Cell Death Dis. 2018;9(3):263.

32. Siegel R L, Miller K D, Jemal A. Cancer statistics, 2020. CA Cancer J Clin. 2020;70(1):7-30.

33. Pascual S, Herrera I, Irurzun J. New advances in hepatocellular carcinoma. World J Hepatol. 2016;8(9):421-438.

34. De Stefano F, Chacon E, Turcios L, Marti F, Gedaly R. Novel biomarkers in hepatocellular carcinoma. Dig Liver Dis. 2018;50(11):1115-1123.

35. Robichaud N, Sonenberg N, Ruggero D, Schneider R J. Translational Control in Cancer. Cold Spring Harb Perspect Biol. 2019;11(7):a32896.

36. Sonenberg N, Hinnebusch A G. Regulation of translation initiation in eukaryotes: mechanisms and biological targets. Cell. 2009;136(4):731-745.

37. Xu T, Zong Y, Peng L, Kong S, Zhou M, Zou J, et al. Overexpression of elF4E in colorectal cancer patients is associated with liver metastasis. Onco Targets Ther. 2016;9:815-822.

38. Humphries M P, Sundara R S, Droop A, Suleman C, Carbone C, Nilsson C, et al. A Case-Matched Gender Comparison Transcriptomic Screen Identifies elF4E and elF5 as Potential Prognostic Markers in Male Breast Cancer. Clin Cancer Res. 2017;23(10):2575-2583.

39. Guan X Y, Fung J M, Ma N F, Lau S H, Tai L S, Xie D, et al. Oncogenic role of elF-5A2 in the development of ovarian cancer. Cancer Res. 2004;64(12):4197-4200.

40. Gao Y, Teng J, Hong Y, Qu F, Ren J, Li L, et al. The oncogenic role of EIF3D is associated with increased cell cycle progression and motility in prostate cancer. Med Oncol. 2015;32(7):518.

41. De Marco N, Tussellino M, Vitale A, Campanella C. Eukaryotic initiation factor 6 (eif6) overexpression affects eye development in Xenopus laevis. Differentiation. 2011;82(2):108-115. 
42. Basu U, Si K, Warner J R, Maitra U. The Saccharomyces cerevisiae TIF6 gene encoding translation initiation factor 6 is required for 60 S ribosomal subunit biogenesis. Mol Cell Biol. 2001;21(5):14531462.

43. Golob-Schwarzl N, Wodlej C, Kleinegger F, Gogg-Kamerer M, Birkl-Toeglhofer A M, Petzold J, et al. Eukaryotic translation initiation factor 6 overexpression plays a major role in the translational control of gallbladder cancer. J Cancer Res Clin Oncol. 2019;145(11):2699-2711.

44. Evan G I, Vousden K H. Proliferation, cell cycle and apoptosis in cancer. Nature. 2001;411(6835):342348.

45. Bernhart E, Damm S, Heffeter P, Wintersperger A, Asslaber M, Frank S, et al. Silencing of protein kinase D2 induces glioma cell senescence via p53-dependent and -independent pathways. Neuro Oncol. 2014;16(7):933-945.

46. Wu Z H, Lin C, Liu C C, Jiang W W, Huang M Z, Liu X, et al. MiR-616-3p promotes angiogenesis and EMT in gastric cancer via the PTEN/AKT/mTOR pathway. Biochem Biophys Res Commun. 2018;501(4):1068-1073.

47. Mai S, Xiao R, Shi L, Zhou X, Yang T, Zhang M, et al. MicroRNA-18a promotes cancer progression through SMG1 suppression and mTOR pathway activation in nasopharyngeal carcinoma. Cell Death Dis. 2019;10(11):819.

48. Wang H, Liu Y, Ding J, Huang Y, Liu J, Liu N, et al. Targeting mTOR suppressed colon cancer growth through 4EBP1/elF4E/PUMA pathway. Cancer Gene Ther. 2020;27(6):448-460.

49. Zakaria C, Sean P, Hoang H D, Leroux L P, Watson M, Workenhe S T, et al. Active-site mTOR inhibitors augment HSV1-dICPO infection in cancer cells via dysregulated elF4E/4E-BP axis. PLoS Pathog. 2018;14(8):e1007264.

50. Harris T E, Chi A, Shabanowitz J, Hunt D F, Rhoads R E, Lawrence J J. mTOR-dependent stimulation of the association of elF4G and elF3 by insulin. EMBO J. 2006;25(8):1659-1668.

51. Golob-Schwarzl N, Krassnig S, Toeglhofer A M, Park Y N, Gogg-Kamerer M, Vierlinger K, et al. New liver cancer biomarkers: PI3K/AKT/mTOR pathway members and eukaryotic translation initiation factors. Eur J Cancer. 2017;83:56-70.

\section{Tables}

Table 1 The antibodies used in the experiments 


\begin{tabular}{|llll|}
\hline Antibody & No. & Company & Country \\
\hline Anti-elF6 & HPA040873 & Sigma & USA \\
\hline Anti-3-actin & $\# 4970$ & CST & USA \\
\hline Anti-mTOR & $\# 2972$ & CST & USA \\
\hline Anti-p-mTOR Ser2448 & $\# 2971$ & CST & USA \\
\hline Anti-Caspase-3 & $\# 9662$ & CST & USA \\
\hline Anti-Cleaved-Caspase-3 & $\# 9664$ & CST & USA \\
\hline Anti-CDK4 & $11026-1-A P$ & Proteintech & USA \\
\hline Anti-CDK6 & $14052-1-A P$ & Proteintech & USA \\
\hline Anti-CCND1 & $26939-1-A P$ & Proteintech & USA \\
\hline Anti-MYC & $16286-1-A P$ & Proteintech & USA \\
\hline Anti-CTNNBL1 & $13665-1-A P$ & Proteintech & USA \\
\hline Anti-Rabbit antibody & SA00001-2 & Proteintech & USA \\
\hline Anti-Ki-67 & ZM-0166 & ZSGB-BIO & China \\
\hline
\end{tabular}

CST: Cell Signaling Technology

Table 2 Clinicopathologic characteristics of elF6 expression in HCC patients 


\begin{tabular}{|c|c|c|c|c|c|}
\hline $\begin{array}{l}\text { Clinicopathological } \\
\text { variables }\end{array}$ & $\mathbf{N}$ & $\begin{array}{l}\text { High } \\
\text { expression }\end{array}$ & Low expression & $x^{2}$ & $\mathrm{p}$ value \\
\hline All casses & 68 & 44 & 24 & & \\
\hline \multicolumn{6}{|l|}{ Gender } \\
\hline Male & 59 & $37 \rrbracket 62.7 \% \rrbracket$ & $22 \llbracket 37.3 \% \rrbracket$ & \multirow[t]{2}{*}{0.765} & \multirow[t]{2}{*}{0.382} \\
\hline Female & 9 & $7 \rrbracket 77.8 \% \rrbracket$ & $2 \rrbracket 22.2 \% \rrbracket$ & & \\
\hline \multicolumn{6}{|l|}{ Age } \\
\hline$\leq 57$ & 34 & $21 \rrbracket 61.8 \% \bigotimes$ & $13 \llbracket 38.2 \% \rrbracket$ & \multirow[t]{2}{*}{0.258} & \multirow[t]{2}{*}{0.612} \\
\hline$\otimes 57$ & 34 & $23 \rrbracket 67.6 \% \rrbracket$ & $11 \otimes 32.4 \% \rrbracket$ & & \\
\hline \multicolumn{6}{|c|}{ Tumour size (diameter in cm) } \\
\hline$\rrbracket 6$ & 33 & $15 \rrbracket 45.5 \% \bigotimes$ & $18 \rrbracket 54.5 \% \rrbracket$ & \multirow[t]{2}{*}{10.405} & \multirow[t]{2}{*}{0.001} \\
\hline$\geq 6$ & 35 & $29 \rrbracket 82.9 \% \bigotimes$ & $6 \bigotimes 17.1 \% \bigotimes$ & & \\
\hline \multicolumn{6}{|l|}{ Differentiation } \\
\hline Well & 9 & $6 \rrbracket 66.7 \% \rrbracket$ & $3 \rrbracket 33.3 \% \rrbracket$ & \multirow[t]{3}{*}{0.286} & \multirow[t]{3}{*}{0.355} \\
\hline Moderate & 52 & $35 \rrbracket 67.3 \% \bigotimes$ & $17 \rrbracket 32.7 \% \rrbracket$ & & \\
\hline Poor & 7 & $4 \rrbracket 57.1 \% \rrbracket$ & $3 \rrbracket 42.9 \% \rrbracket$ & & \\
\hline \multicolumn{6}{|l|}{ Vascular invasion } \\
\hline No & 28 & $11 \rrbracket 39.3 \% \rrbracket$ & 17囚60.7\%区 & \multirow[t]{2}{*}{13.468} & \multirow[t]{2}{*}{0.000} \\
\hline Yes & 40 & $33 \llbracket 82.5 \% \rrbracket$ & $7 \rrbracket 17.5 \% \rrbracket$ & & \\
\hline \multicolumn{6}{|c|}{ Lymphatic metastasis } \\
\hline No & 50 & $31 \rrbracket 62.0 \% \rrbracket$ & $19 \llbracket 38.0 \% \rrbracket$ & \multirow[t]{2}{*}{0.230} & \multirow[t]{2}{*}{0.632} \\
\hline Yes & 18 & $10 \rrbracket 55.6 \% \rrbracket$ & $8 \rrbracket 44.4 \% \rrbracket$ & & \\
\hline \multicolumn{6}{|l|}{ Distant metastasis } \\
\hline No & 41 & $25 \llbracket 61.0 \% \rrbracket$ & 16囚39.0\%区 & \multirow[t]{2}{*}{0.629} & \multirow[t]{2}{*}{0.428} \\
\hline Yes & 27 & 19ه70.4\%区 & $8 \rrbracket 29.6 \% \rrbracket$ & & \\
\hline \multicolumn{6}{|l|}{ Hepatitis B } \\
\hline No & 19 & $11 \rrbracket 57.9 \% \rrbracket$ & $8 \rrbracket 42.1 \% \rrbracket$ & \multirow[t]{2}{*}{0.043} & \multirow[t]{2}{*}{0.835} \\
\hline Yes & 49 & $27 \rrbracket 55.1 \% \bigotimes$ & $22 \llbracket 44.9 \% \rrbracket$ & & \\
\hline AFP level ( $\mathrm{ng} / \mathrm{ml}$ ) & & & & & \\
\hline
\end{tabular}




\begin{tabular}{|c|c|c|c|c|c|}
\hline$\leq 400$ & 53 & $34 \llbracket 64.2 \% \rrbracket$ & 19ه35.8\%】 & \multirow[t]{2}{*}{0.032} & \multirow[t]{2}{*}{0.857} \\
\hline$\otimes 400$ & 15 & 10ه66.7\%】 & $5 \rrbracket 33.3 \% \rrbracket$ & & \\
\hline \multicolumn{6}{|c|}{ Cirrhosis } \\
\hline No & 33 & $24 \bigotimes 72.7 \% \rrbracket$ & $9 \rrbracket 27.3 \% \rrbracket$ & \multirow[t]{2}{*}{1.806} & \multirow[t]{2}{*}{0.179} \\
\hline Yes & 35 & $20 \rrbracket 57.1 \% \rrbracket$ & $15 \rrbracket 42.9 \% \rrbracket$ & & \\
\hline
\end{tabular}

Bold indicates p-value $<0.05$.

\section{Figures}
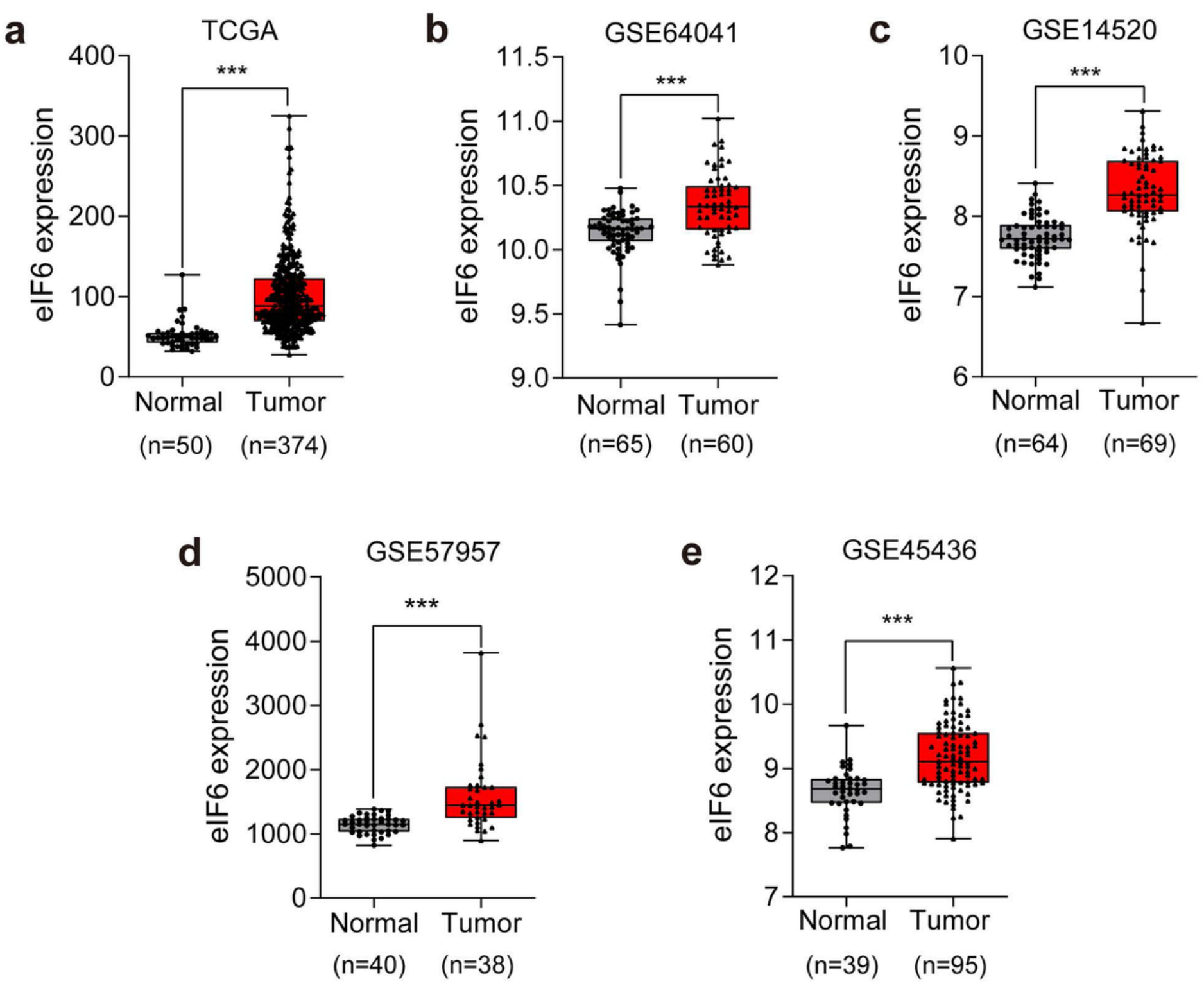

Figure 1 
Bioinformatics analysis showed that elF6 was upregulated in HCC tissues. a The expression level of elF6 in HCC tissues $(n=374)$ was upregulated compared with that of normal tissues $(n=50)$ in the TCGA database. b-e The expression level of elF6 in HCC tissues was upregulated compared with that of normal tissues in the GEO database, including GSE64041 (Normal=65, Tumor=60), GSE14520 (Normal=64, Tumor=69), GSE57957 (Normal=40, Tumor=38), and GSE45436 (Normal=39, Tumor= 95). ${ }^{\star \star \star} p<0.001$. elF6, eukaryotic translation initiation factor 6; HCC, hepatocellular carcinoma; TCGA, The Cancer Genome Atlas; GEO, Gene Expression Omnibus.

a

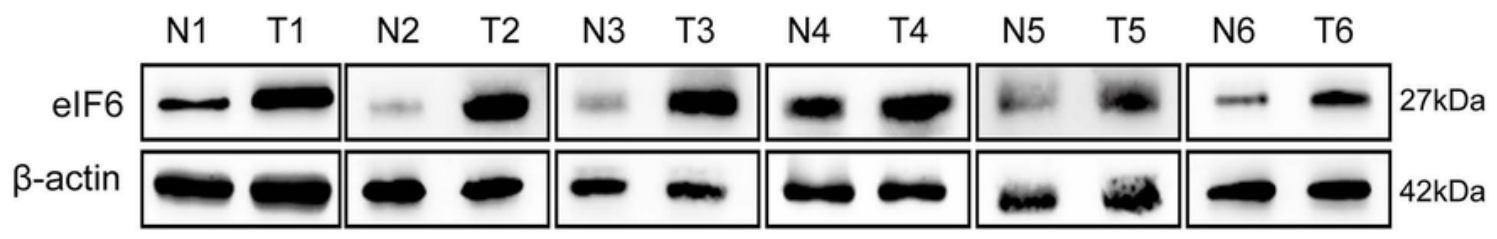

b
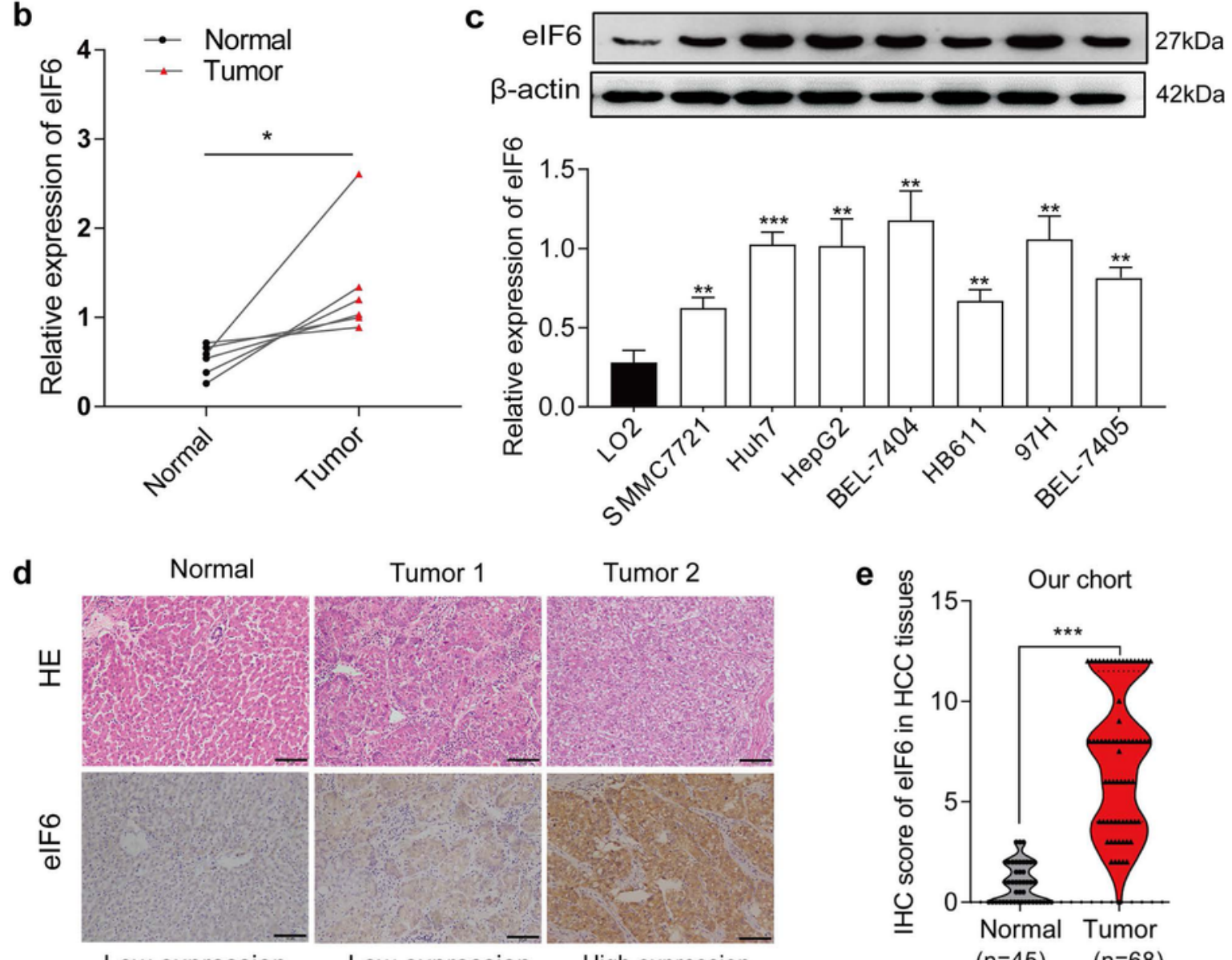

Tumor 2
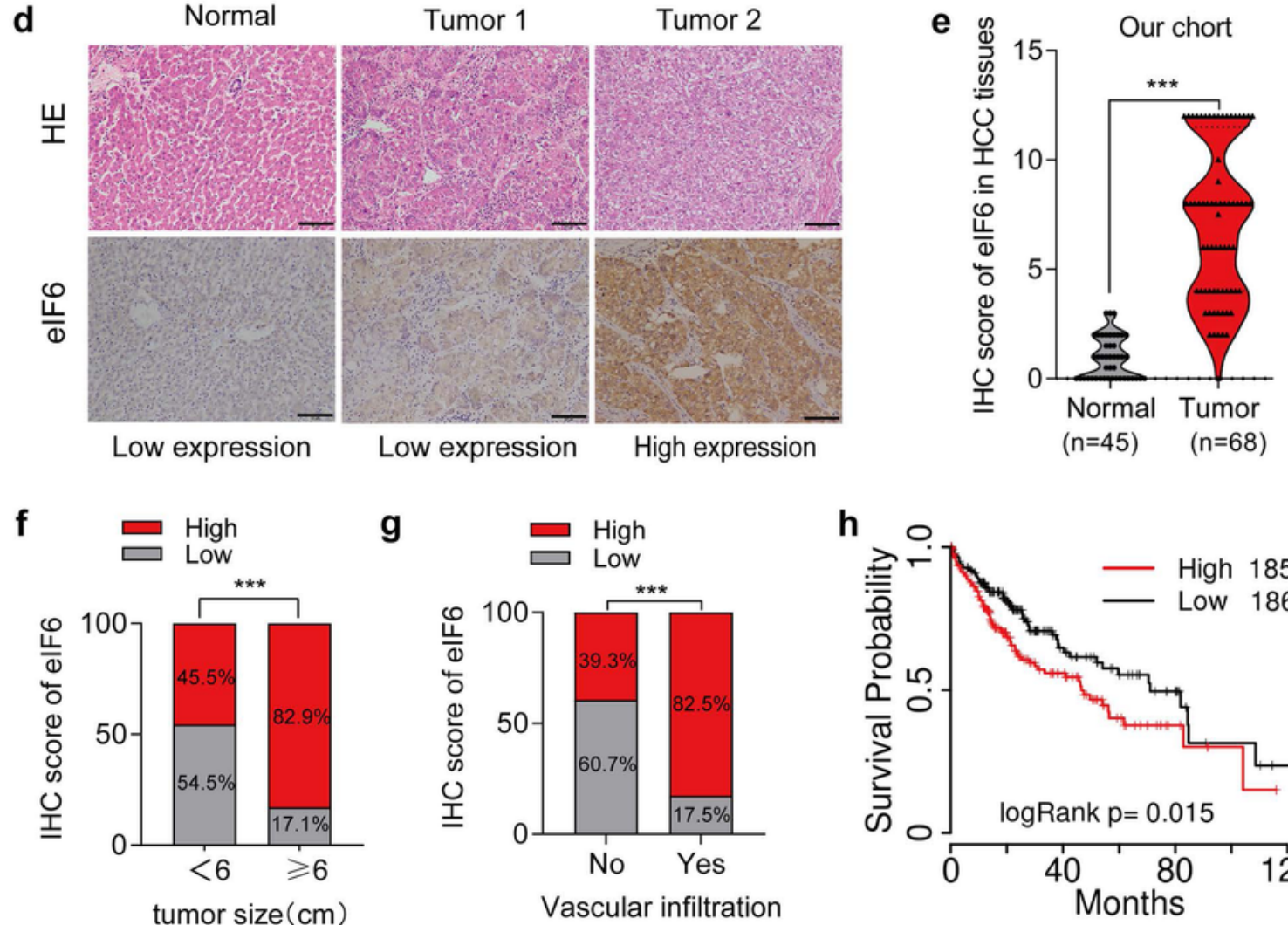

g
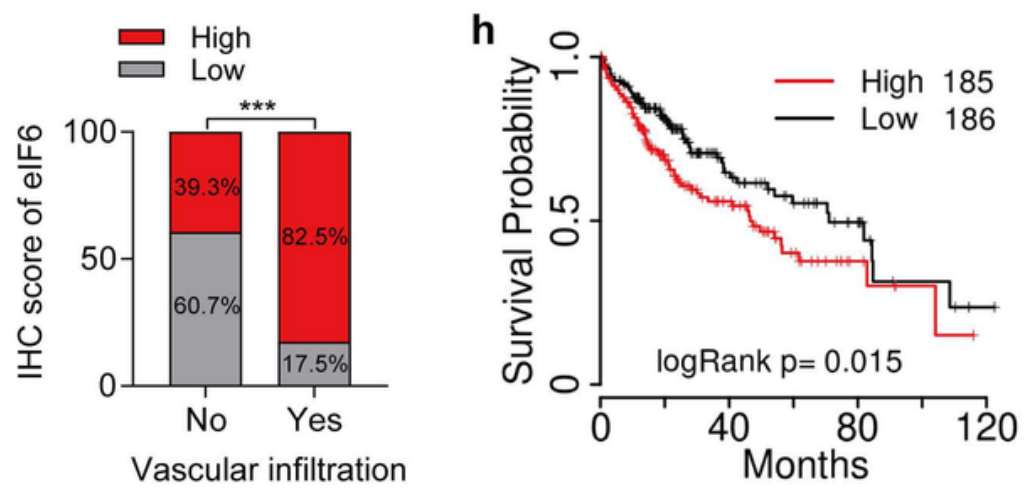


\section{Figure 2}

Upregulation of elF6 is correlated with HCC progression and poor prognosis. a, b The expression levels of elF6 protein were detected by western blot in 6 pairs of fresh surgically resected human HCC tissues. $\beta$ actin was used as an internal control. The density of elF6/ $\beta$-actin was calculated as the relative expression levels of elF6 protein. T, HCC tissues; N, paired adjacent normal liver tissues. c Western blot analysis of elF6 protein levels in $7 \mathrm{HCC}$ cell lines. The data indicate the means \pm SD $(n=3)$. d HE staining and IHC staining of elF6 antibody in normal liver tissues and HCC tissues. Low expression and high expression images for elF6 were shown above. Bar=50 $\mu \mathrm{m}$. e The distribution of scores showed that elF6 was more highly expressed in $\mathrm{HCC}(n=68)$ tissues than in normal liver tissues $(n=45)$. $f$ The expression levels of elF6 had a positive correlation with tumor size. $g$ Higher levels of elF6 in HCC patients were more likely to cause vascular invasion. $\mathrm{h}$ Kaplan-Meier analysis of OS based on TCGA database in all 371 patients. Patients with high elF6 expression $(n=185)$ had a more dismal OS than patients with low elF6 expression $(n=186)$ in HCC. Color images are available online. The error bar represents the mean \pm SD $(n=3)$. OS, overall survival. ${ }^{*} p<0.05 ;{ }^{* *} p<0.01$; and ${ }^{* * *} p<0.001$.

a

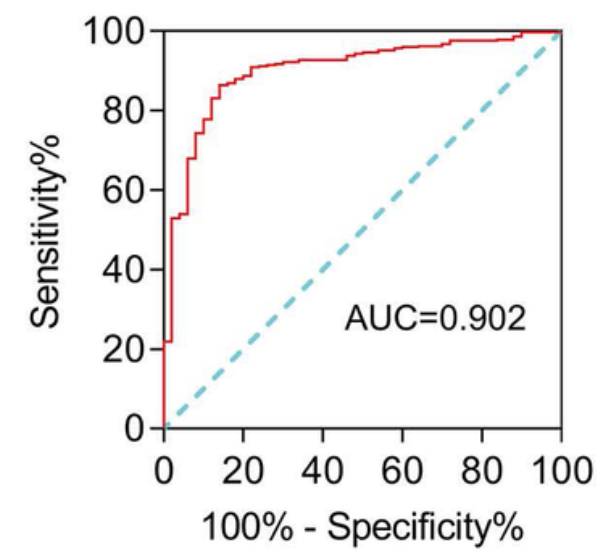

d

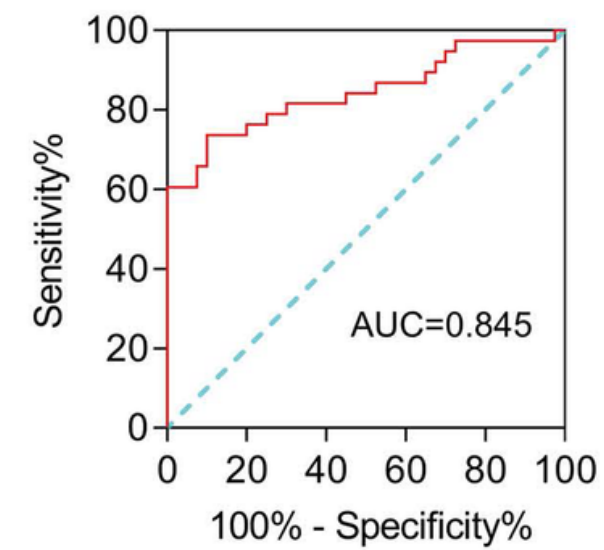

b ROC curve of GSE64041

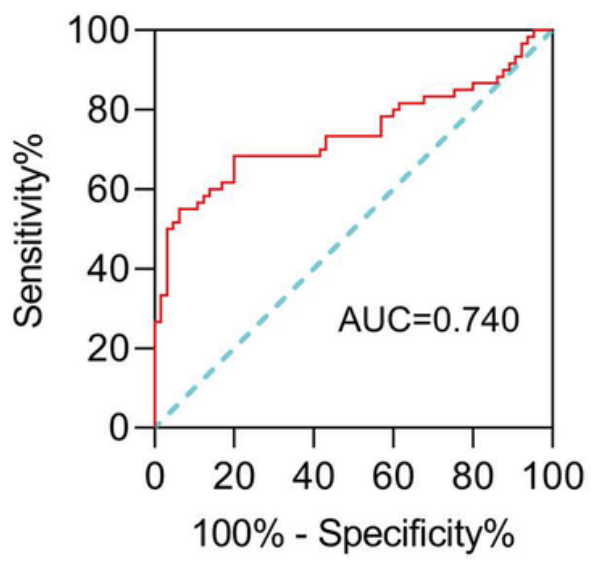

e

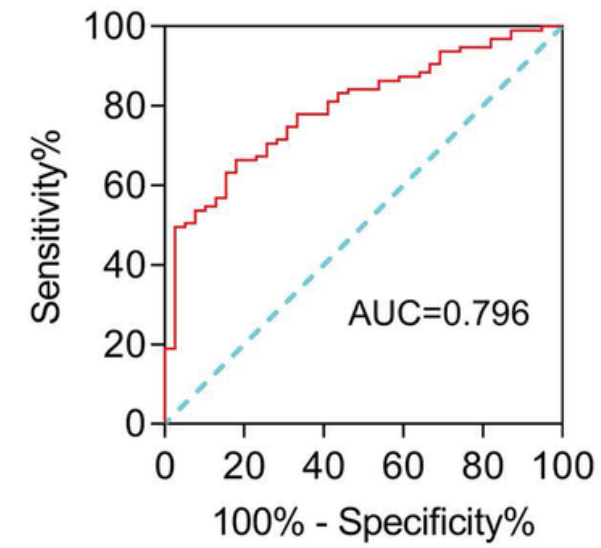

C ROC curve of GSE14520

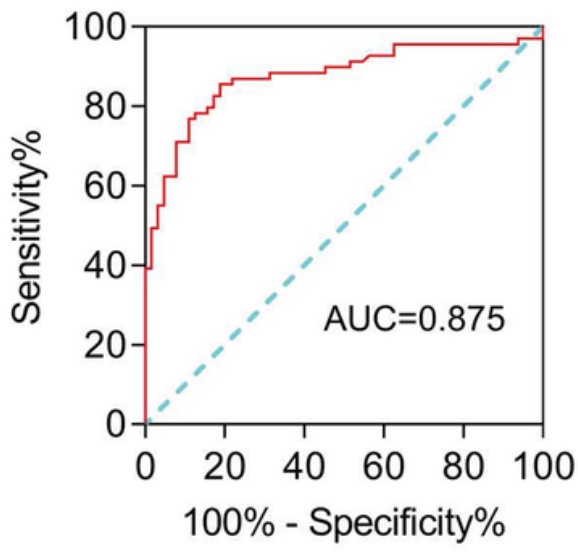

ROC curve of elF6 IHC

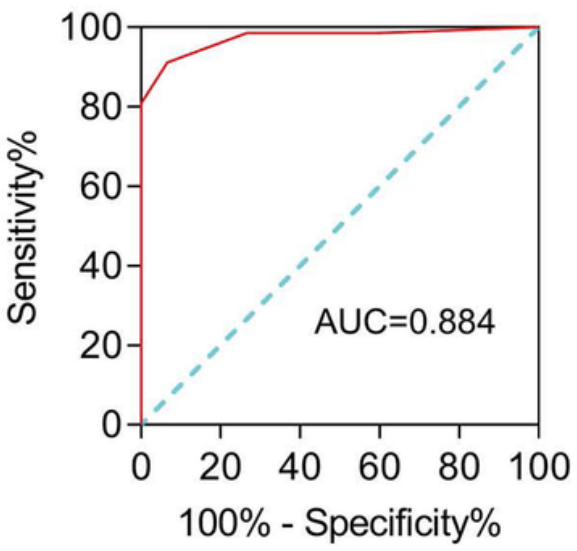

Figure 3 
High expression of elF6 in HCC tissue has reliable diagnostic value. a ROC curve for elF6 expression in normal tissue and HCC tissues from TCGA database, AUC $=0.902$. b-e ROC curve for elF6 expression in the following datasets from the GEO database: GSE64041 (AUC=0.740), GSE14520 (AUC=0.875), GSE57957 $(A U C=0.845)$ and GSE45436 (AUC=0.796). $\mathrm{f}$ Validation of elF6 diagnosis value was confirmed in our IHC results of HCC, AUC=0.884. ROC, Receiver Operating Characteristic; AUC, Area Under Curve.

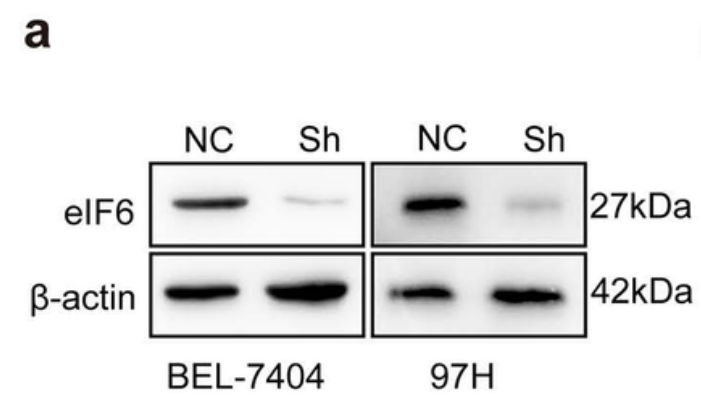

d
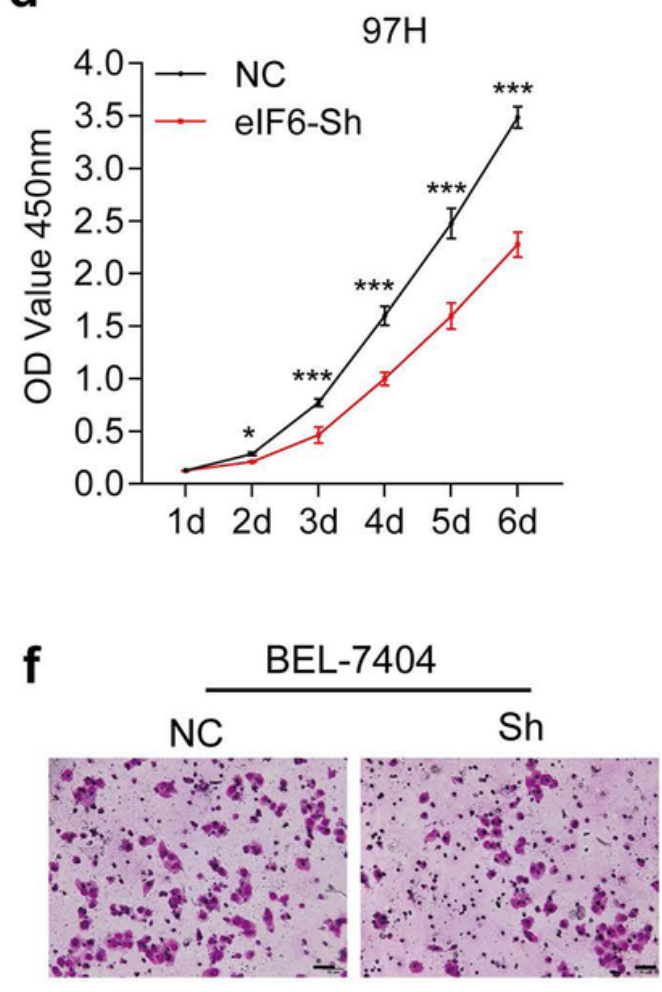
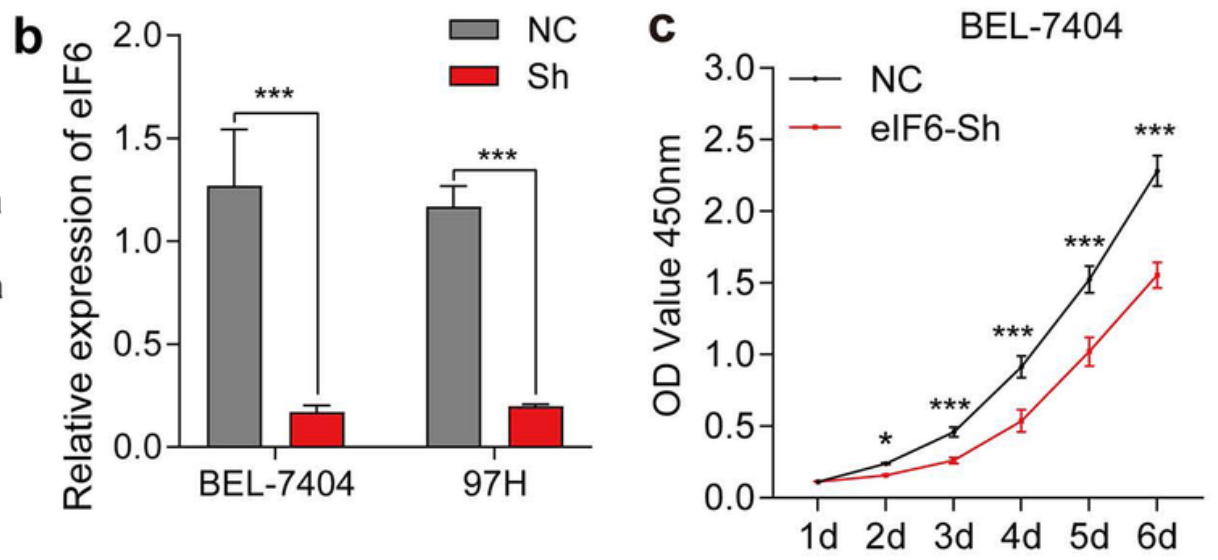

e
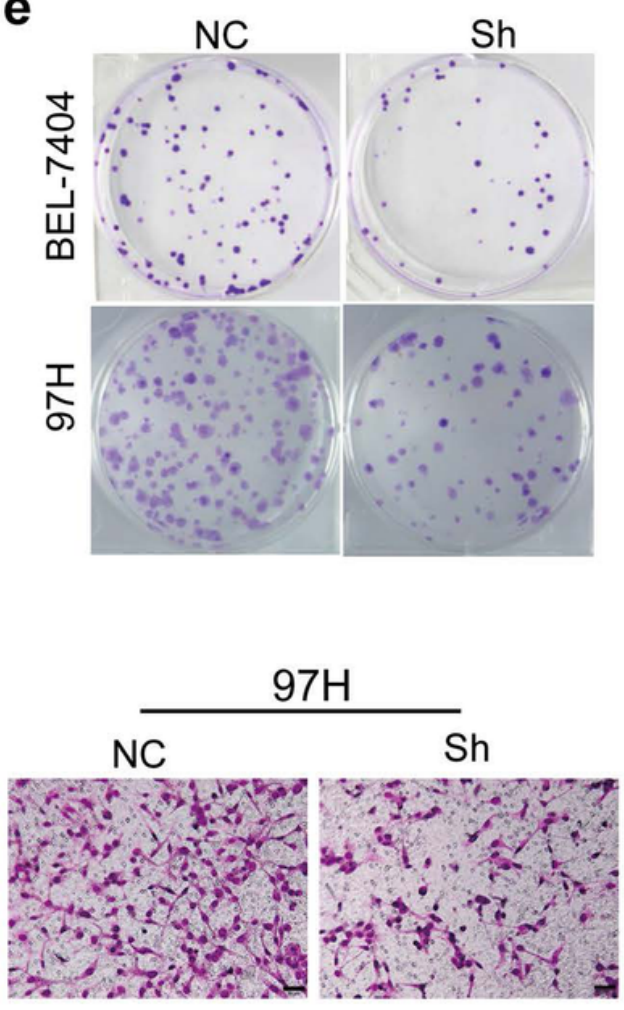
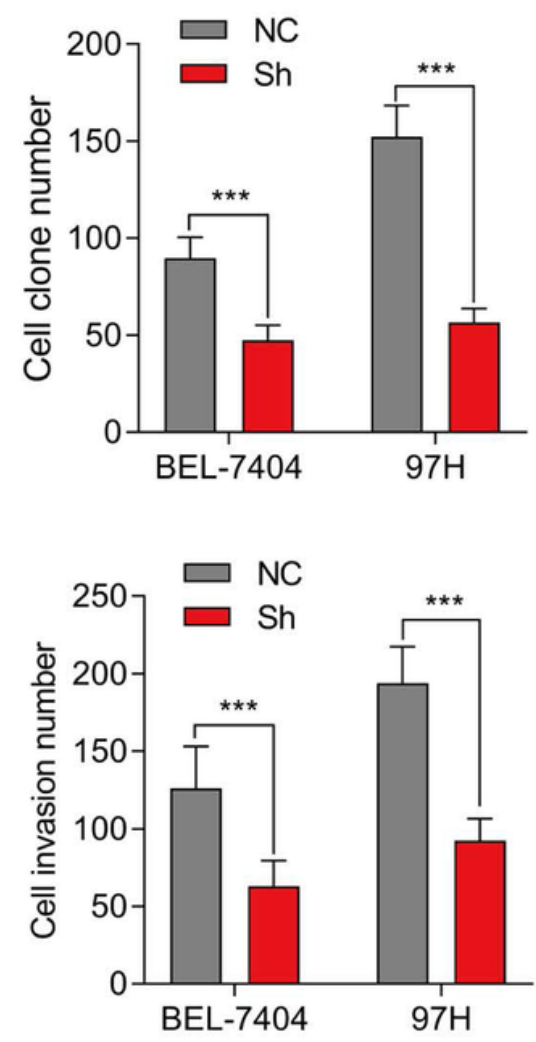

\section{Figure 4}

Knockdown of elF6 inhibited the proliferation and invasion of HCC cells in vitro. a, b Western blot analysis identified the infection efficiency of knockdown elF6 lentiviruses in HCC cells. c, d CCK-8 assays were used to determine the cell proliferation rate in $\mathrm{HCC}$ cells infected with knockdown elF6 lentiviruses. e Colony formation ability of elF6 knockdown was detected by plate colony formation assays. $f$ Transwell- 
Matrigel assays were used to measure the invasion ability of HCC cells with elF6 knockdown. Bar $=50 \mu \mathrm{m}$. The error bar represents the mean \pm SD $(n=3)$. ${ }^{\star} p<0.05 ;{ }^{*} p<0.01$. Sh, Short hairpin RNA for knockdown elF6.
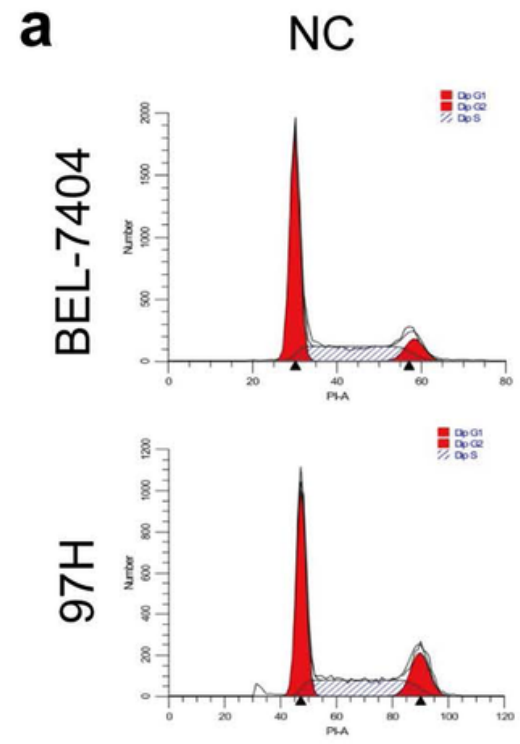

b

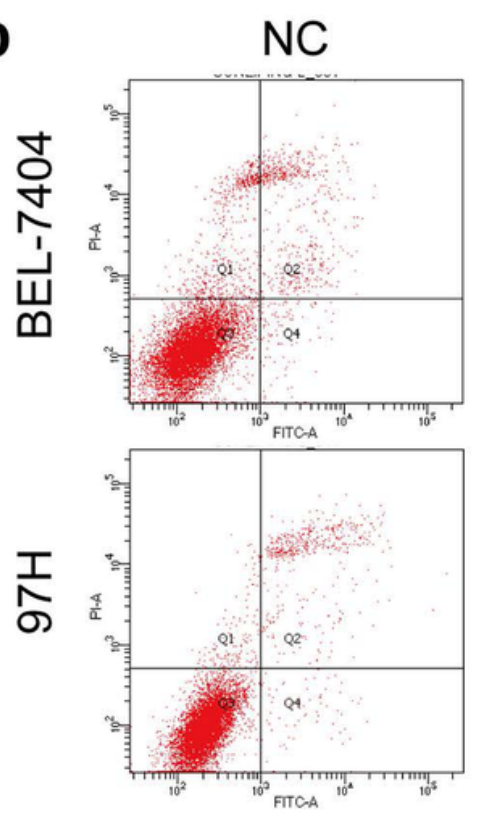

$\mathrm{Sh}$
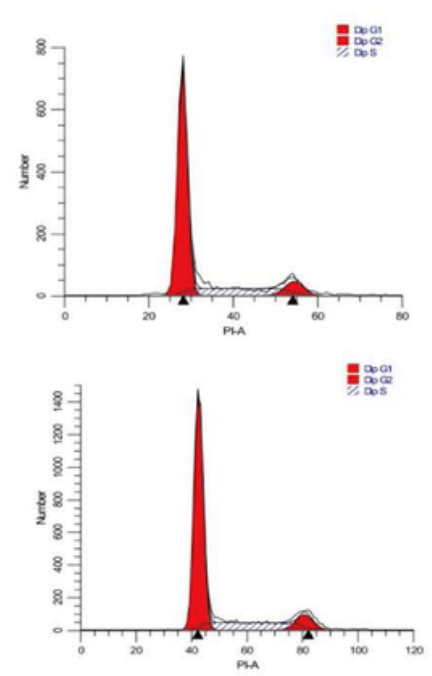

Sh

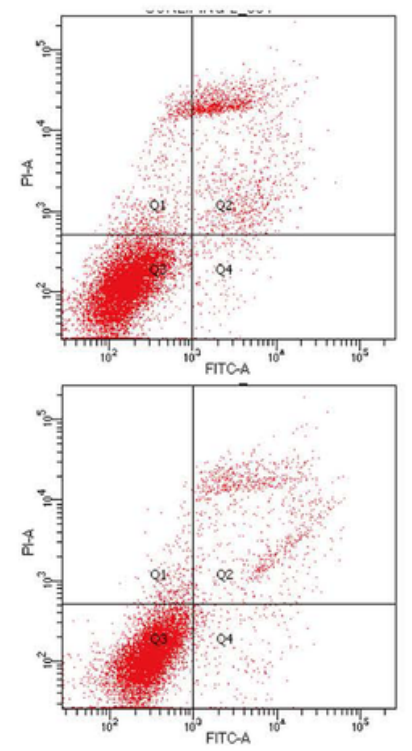

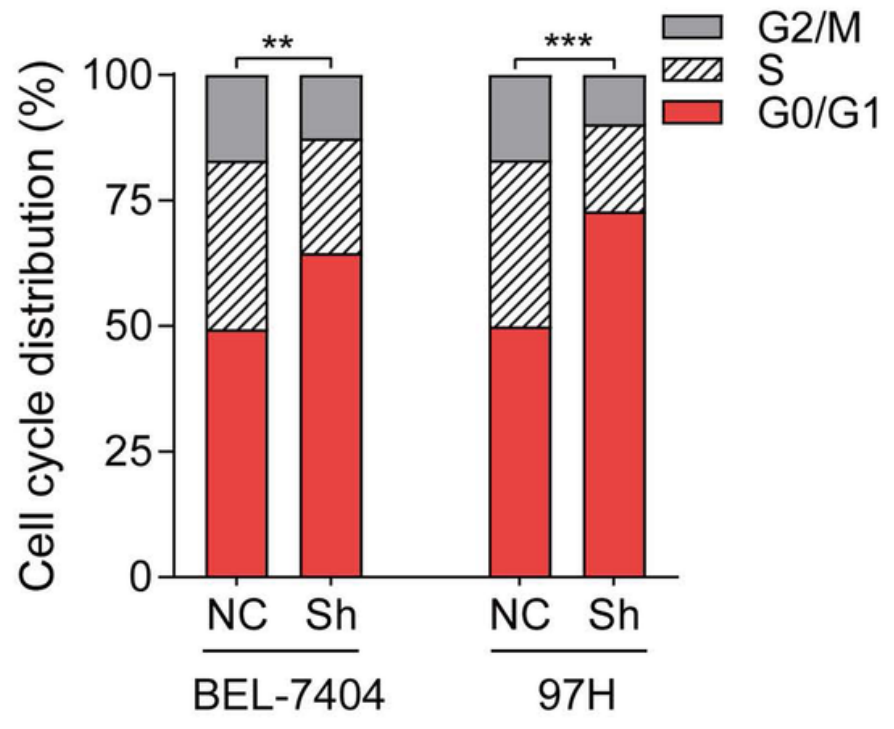

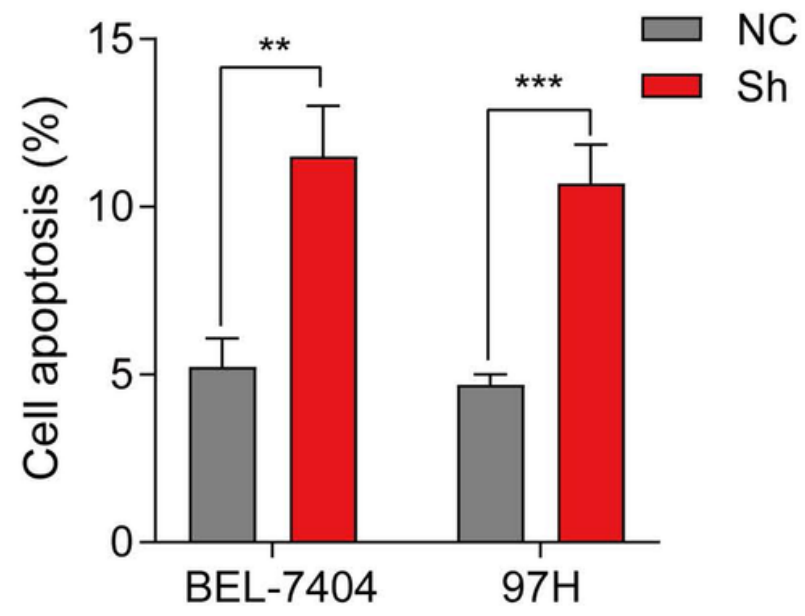

\section{Figure 5}

Knockdown of elF6 induces cell cycle arrest and apoptosis. a The cell cycle distribution was analyzed after knockdown of elF6. b The effect of elF6 knockdown on HCC cell apoptosis was analyzed by flow cytometry. The error bar represents the mean \pm SD $(n=3) .{ }^{*} p<0.05 ;{ }^{* \star} p<0.01$; and ${ }^{* \star *} p<0.001$. 
a

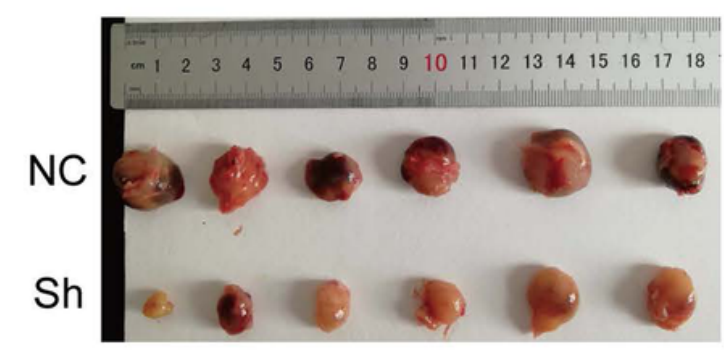

b

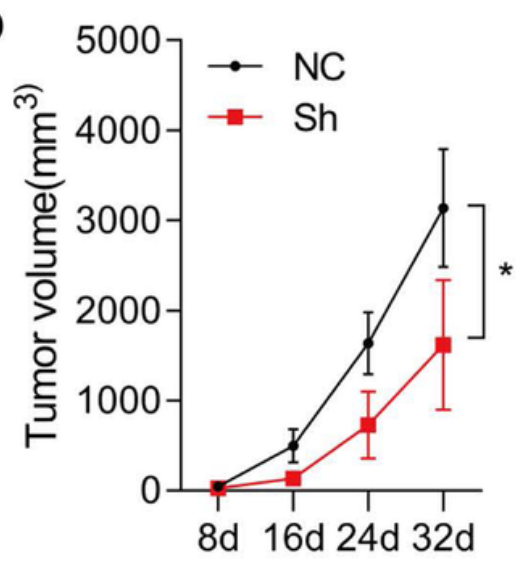

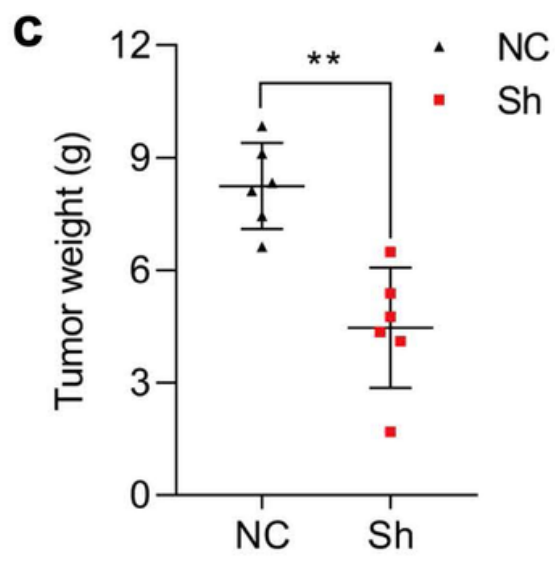

e

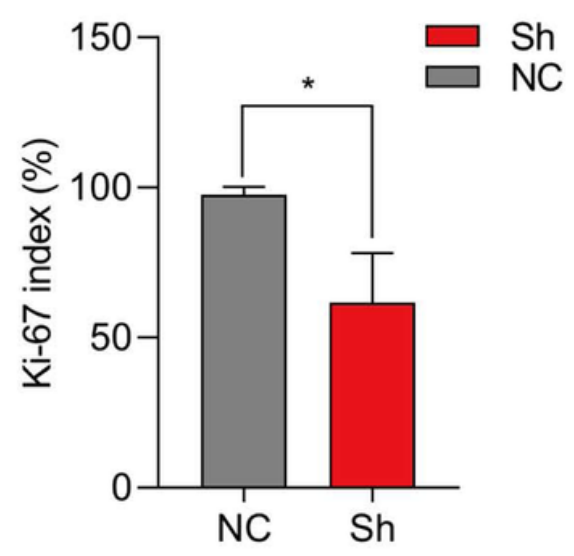

\section{Figure 6}

Knockdown of elF6 in HCC cells reduced the capacity of tumorigenesis in vivo. a Images of tumors formed in BALB/c nude mice injected subcutaneously with elF6-knockdown BEL-7404 cells ( $n=6$ for each group). b The tumor volumes were calculated on the indicated days. $c$ The tumor weights were measured after perfect excision from nude mice. $\mathrm{d}$ HE staining and $\mathrm{IHC}$ staining of $\mathrm{Ki}-67$ antibody in sections of subcutaneous tumors. Bar $=50 \mu \mathrm{m}$. e The Ki-67 index was calculated according to the number of Ki-67positive cells divided by the number of total cells $\times 100 \%$. The error bar represents the mean $\pm S D(n=6)$. ${ }^{*} p<0.05$; and ${ }^{*} p<0.01$. 


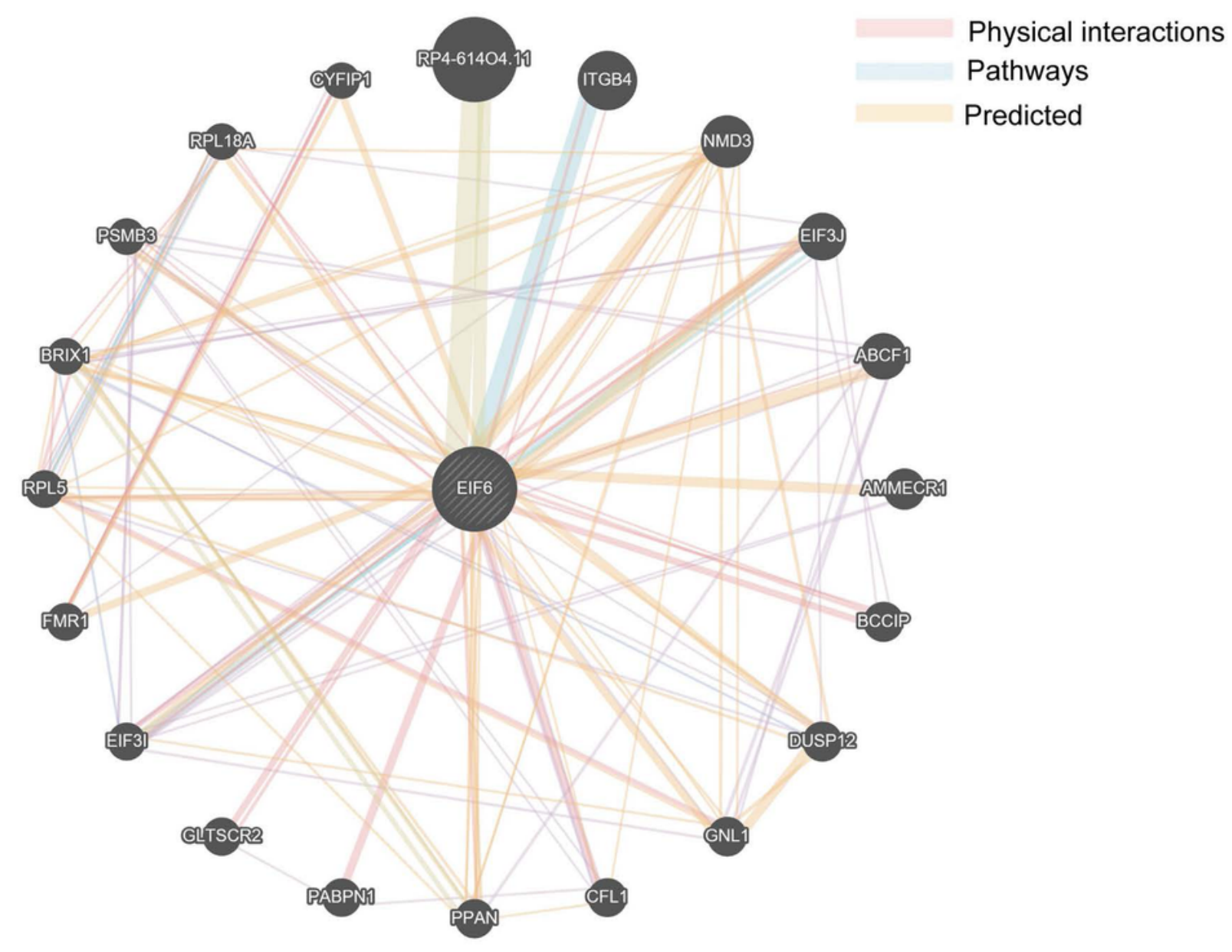

b

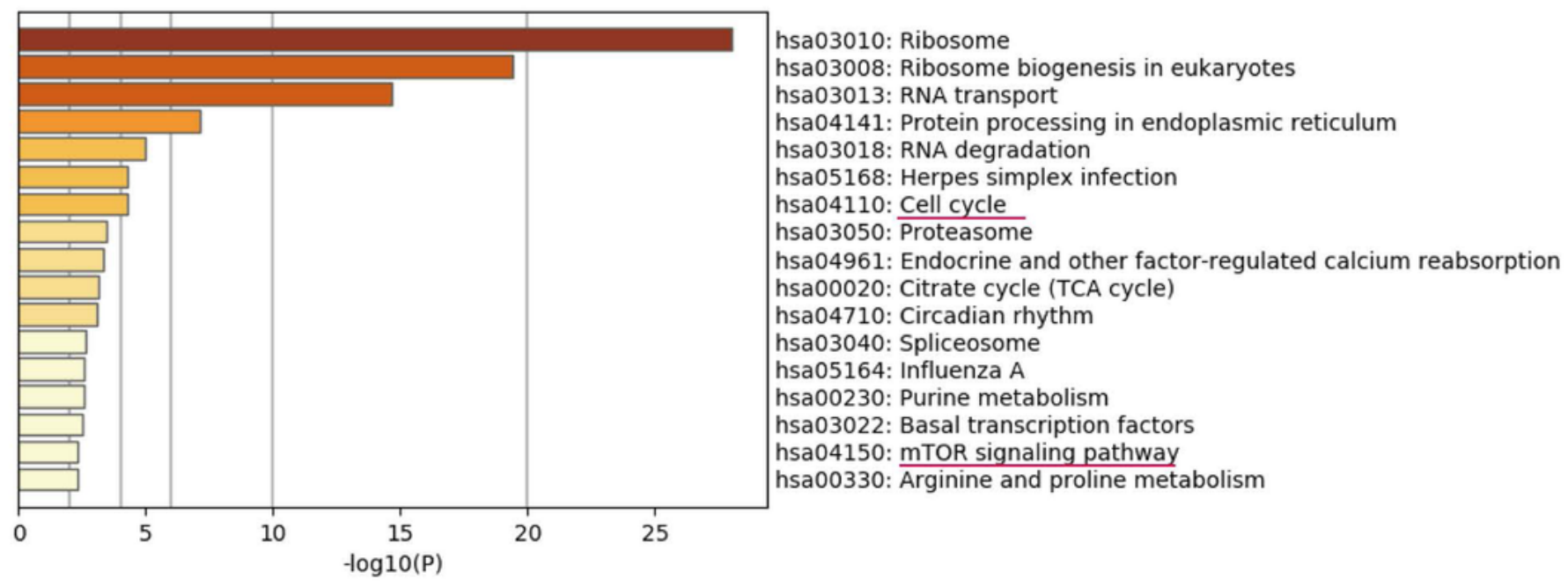

Figure 7

The potential enrichment pathways of elF6 were predicted by the UniHI and Metascape databases. a The potential regulation of elF6 in HCC. elF6-centered gene-gene functional interaction network showing the genes with physical interactions, shared signaling pathways, and predicted interactions with elF6. Color images are available online. b The signaling pathway enrichment analysis showed that elF6 was associated with the cell cycle and mTOR signaling pathways. 
a

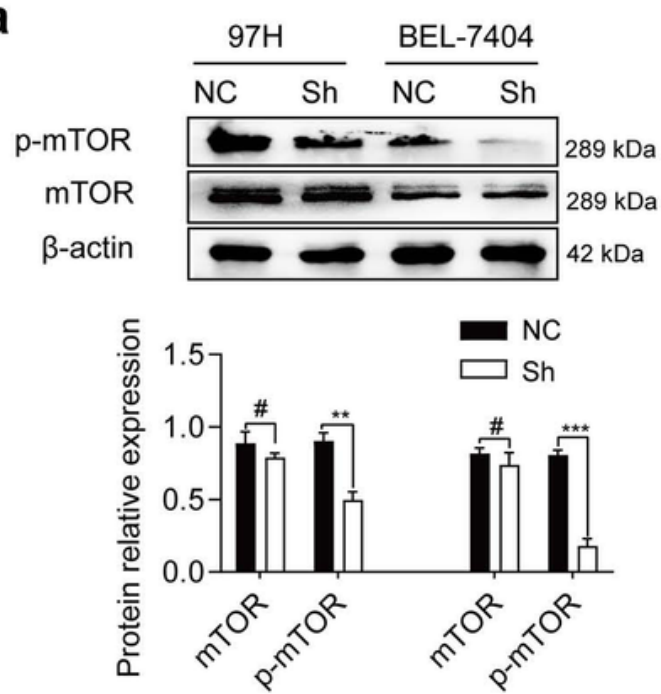

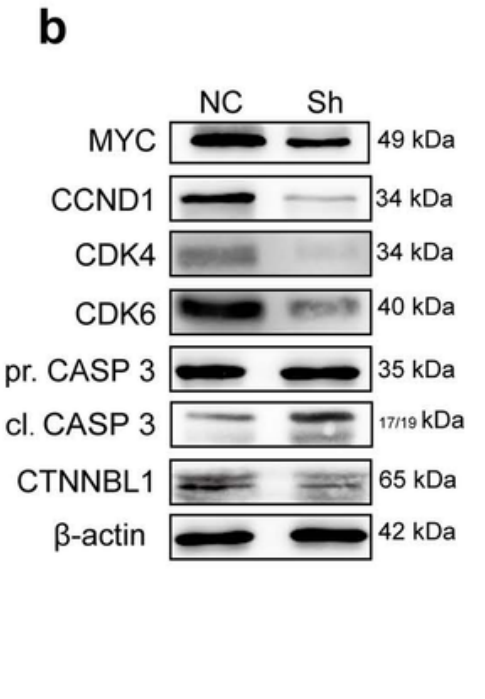

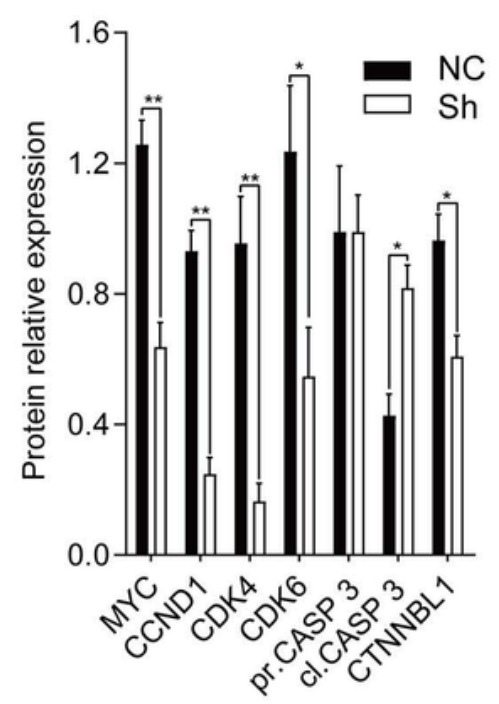

C

$r=0.505 p<0.001 n=373$

d

$\mathrm{R}=0.403 \quad P<0.001 \mathrm{n}=373$
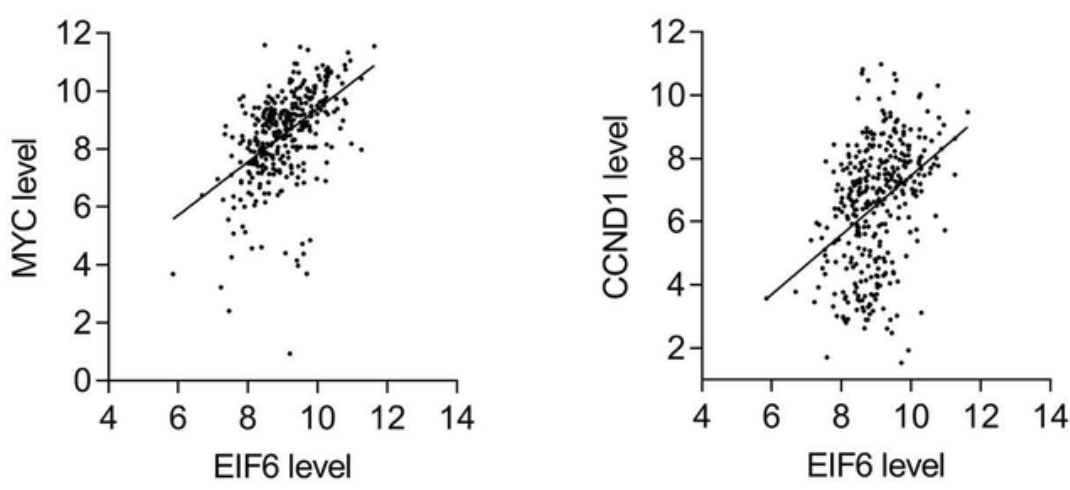

f

$R=0.334 P<0.001 n=373$

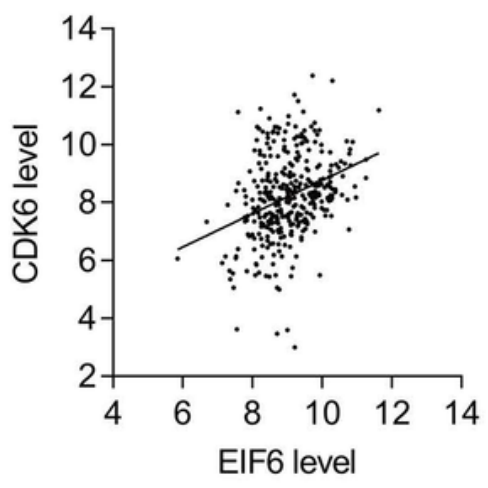

g

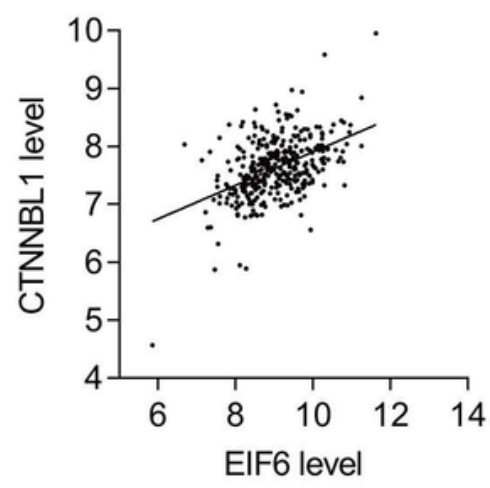

e $\mathrm{R}=0.6761 P<0.001 \mathrm{n}=373$

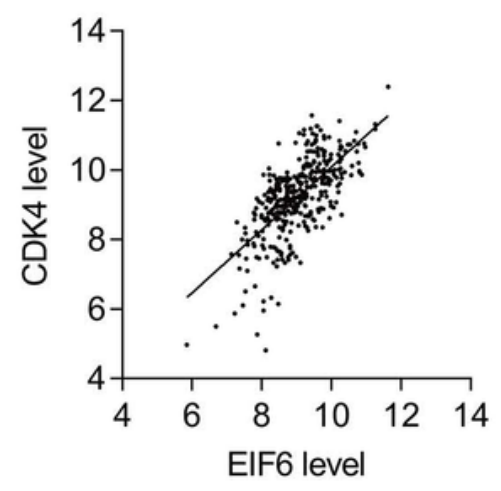

h

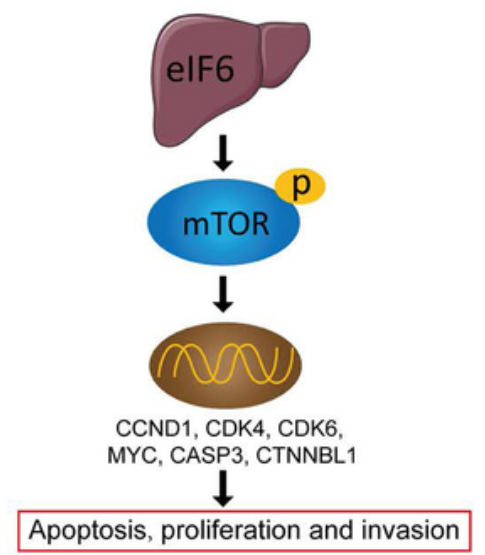

Figure 8

elF6 activated mTOR-related cancer signaling pathways in HCC progression. a Western blotting was used to measure the expression level of mTOR-related markers in HCC cells with elF6 knockdown. b Western blotting was used to analyze the expression levels of cell cycle, apoptosis and invasion regulators, including MYC, CCND1, CDK4, CDK6, cleaved-CASP3 (cl. CASP3), pro-CASP3 (pr. CASP3) and CTNNBL1. c-g Analysis of the correlation coefficient between elF6 and cell progression-related genes shown by 
western blot analysis using the R2 database $(n=373)$. h A working model by which elF6 activated mTORrelated cancer signaling pathways in HCC progression. $\# p>0.05 ;{ }^{*} p<0.05 ;{ }^{* \star} p<0.01$; and ${ }^{\star \star \star} p<0.001$.

\section{Supplementary Files}

This is a list of supplementary files associated with this preprint. Click to download.

- LipingSunSupplementaryTableS1.xlsx

- LipingSunSupplementaryTableS2.xlsx

- LipingSunSupplementaryTableS3.xlsx 